Portland State University

PDXScholar

Fall 2017

\title{
Using High Resolution Archived Transit Data to Quantify Congestion at Intersections of Urban Arterials
}

Travis Bradley Glick

Portland State University

Follow this and additional works at: https://pdxscholar.library.pdx.edu/honorstheses

Let us know how access to this document benefits you.

\section{Recommended Citation}

Glick, Travis Bradley, "Using High Resolution Archived Transit Data to Quantify Congestion at Intersections of Urban Arterials" (2017). University Honors Theses. Paper 147.

https://doi.org/10.15760/honors.138

This Thesis is brought to you for free and open access. It has been accepted for inclusion in University Honors Theses by an authorized administrator of PDXScholar. Please contact us if we can make this document more accessible: pdxscholar@pdx.edu. 
Using High Resolution Archived Transit Data to

Quantify Congestion at Intersections of Urban Arterials

By

Travis B. Glick
An undergraduate honors thesis submitted in partial fulfillment of the requirements for the degree of
Bachelor of Science
in
University Honors
and

Civil and Environmental Engineering

Thesis Advisor

Miguel Figliozzi

Portland State University

May 2015 


\begin{abstract}
Congestion can influence transit service attractiveness, operating cost, and system efficiency. This paper examines archived transit data to compare the effects of different intersection geometries on traffic congestion. The Tri-County Metropolitan Transportation District of Oregon (TriMet) has been archiving automatic vehicle location (AVL) and automatic passenger count (APC) data for all bus trips at the stop level since 1997 as part of their bus dispatch system (BDS). In 2013, TriMet implemented a higher resolution bus AVL data collection system. This 5-second resolution (5-SR) bus position data provides information about buses between stops in addition to their stop level data. The 5-SR data allows for the creation of a quantitative congestion analysis at specific locations. The objective of this paper is to use the high-resolution congestion analysis for a particular bus route in Portland, OR to analyze intersections with similar demands (i.e. through bus travel, similar traffic volumes, and far-side bus-stops) but different geometries. Results suggest that buses moving through intersections with a separated right turn lane may experience significantly less congestion than buses moving through intersections with a combination through/right turn lane. Interestingly, the travel lane (i.e. in the right turn or through lane) of the buses also may make a significant difference to the congestion experience by buses at the intersection. Buses in the through lane may experience less delay than buses in the rightturn lane.
\end{abstract}

\title{
Introduction
}

The analysis and modeling of transit travel times and bus performance is important both to transit authorities and to passengers. In 1983, Levinson stated this notion clearly, saying that "Transit Travel times and operating speeds influence service attractiveness, costs, and efficiency. [These factors] also provide important descriptions of system performance for use in the transportation planning process" [1]. This sentiment continues to holds true today; operating speeds (i.e the actual speed that a 
bus can travel) influences travel times (i.e. how quickly passengers can get from point A to point B) and together these factors influence ridership. Unreliable or slow service may lead to increased costs for both operators and users, which, in turn, leads to decreases in bus demand and ridership. Travel demand remains relatively constant in urban areas; when public transit supply decreases, users turn to other transportation modes, most commonly, single occupancy vehicles. This shift away from public transportation often leads to increased congestion and travel times for all users. Bus performance measures that capture bus travel time and reliability can be quantified and transit agencies can prioritize strategies to reduce bus travel time and variability based on these results [2]. This paper provides intersection-level performance metrics based on congestion that can help transit agencies and operators identify intersection geometries that adversely affect traffic flow along urban arterials.

This study analyzed data from US 26 (Powell Blvd.) in Portland, OR and covered Tuesdays, Wednesdays, and Thursdays from the first three weeks in November 2014 for a total of 9 days. The fourth week of November, Thanksgiving week, was excluded from analysis due to holiday bus scheduling. US 26, Powell Blvd., is a major urban arterial in the Portland metropolitan area that connects the city of Gresham to downtown Portland. The entire arterial and route segment is shown in Figure 1. 


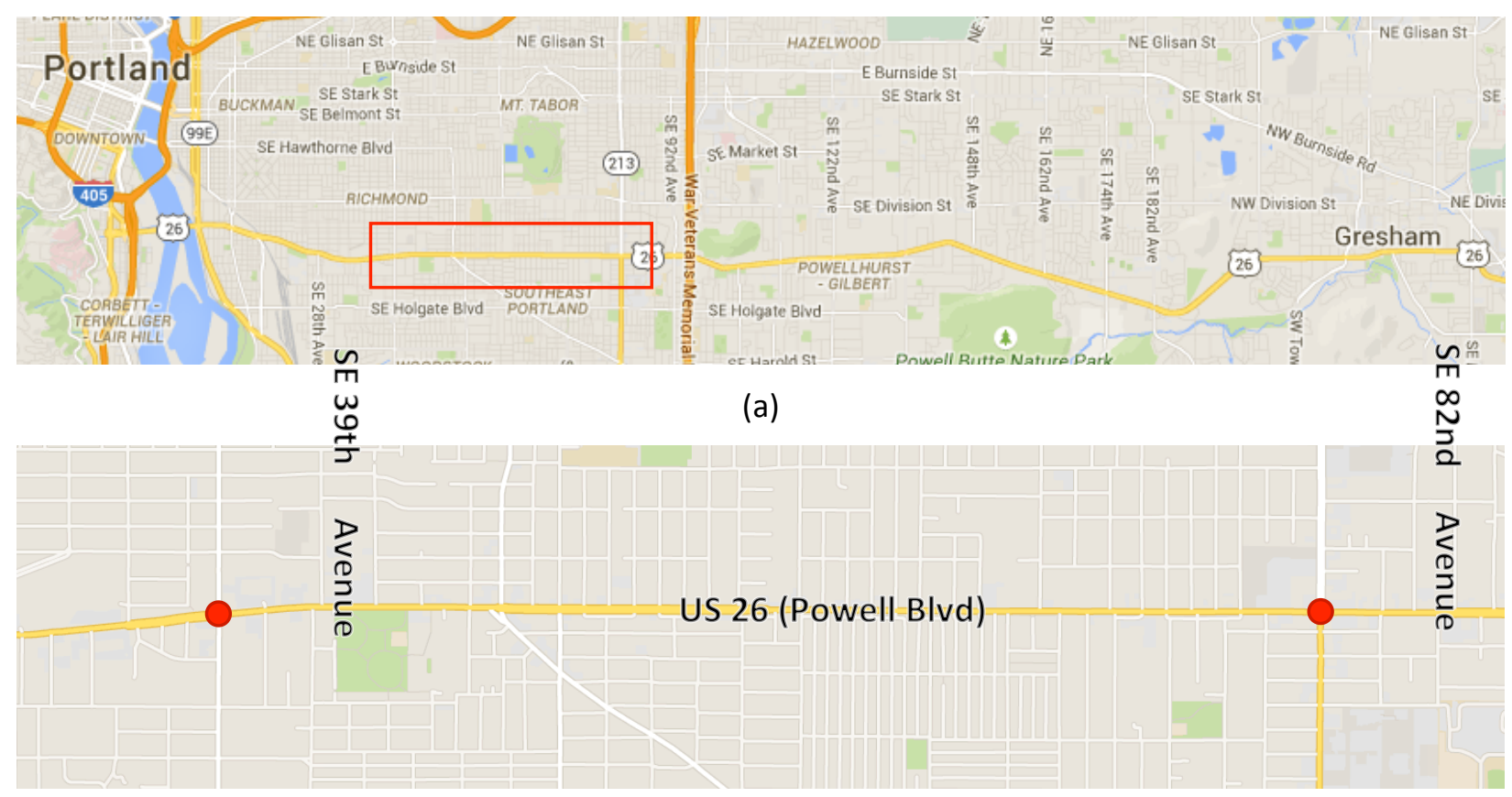

(b)

Figure 1 - (a) US 26 (Powell Blvd) corridor, shown in yellow, connecting Gresham to Portland. Route segment is marked with a red box. (b) Powell Blvd from SE $82^{\text {nd }}$ to SE $39^{\text {th }}$. The intersections included in this analysis are marked with red circles.

Traffic and turning movement counts by the City of Portland were obtained for Feb. 2005 and Sep. 2011 for SE $82^{\text {nd }}$ and SE $39^{\text {th }}$, respectively. Traffic counts differ year to year and month to month due to changes in the economy and weather. These differences, when analyzed over a period of years, create trends that are recorded by Oregon Department of Transportation and can be used to adjust traffic counts from one time period to be compatible with counts from another time period. For the area in question, the February 2005 traffic counts tended to be $<1 \%$ higher than the September 2011 counts [3]. With this information, the counts obtained in each report can be used in tandem with each other for direct comparisons. Traffic volumes are higher on the western segments than the eastern segments of this corridor between $72^{\text {th }}$ and $26^{\text {th }}$ [4]. As shown in Table 1, the turning movement counts varied between the four approaches, but the total PM peak traffic volume is between $15 \%$ and $20 \%$ greater for SE $39^{\text {th }}$ then for SE $82^{\text {nd }}[5][6]$. This knowledge allows for a general comparison of the $39^{\text {th }}$ and $82^{\text {nd }}$ intersections once a correction has been applied. Unfortunately, the differences in the turning 
movements are likely of greater consequence then the total traffic counts of the intersection approaches. While a correction of $15 \%$ will be applied to the SE $82^{\text {nd }}$ intersection, uncertainty remains regarding how much congestion is affected by each traffic movement, signal timing, and the progression of transit signal priority.

Table 1 - Turning Movement Counts for Intersections of Powell Blvd. and SE $82^{\text {nd }}$ and $39^{\text {th }}$ Ave. [5] [6].

\begin{tabular}{|c|c|c|c|c|c|c|c|c|c|c|c|c|c|c|c|c|}
\hline \multirow[b]{4}{*}{$\begin{array}{l}\text { Start } \\
\text { Time }\end{array}$} & \multicolumn{16}{|c|}{ All Counts for SE Powell Blvd. } \\
\hline & \multicolumn{8}{|c|}{ Intersection of SE 82nd Ave. [23 Feb. 2005] } & \multicolumn{8}{|c|}{ Intersection of SE 39th Ave. [20 Sep. 2011] } \\
\hline & \multicolumn{4}{|c|}{ Westbound } & \multicolumn{4}{|c|}{ Eastbound } & \multicolumn{4}{|c|}{ Westbound } & \multicolumn{4}{|c|}{ Eastbound } \\
\hline & Left & Thru & Right & Total & Left & Thru & Right & Total & Left & Thru & Right & Total & Left & Thru & Right & Total \\
\hline $16: 00$ & 52 & 161 & 23 & 236 & 53 & 262 & 50 & 365 & 24 & 211 & 32 & 267 & 51 & 355 & 35 & 441 \\
\hline 16:15 & 45 & 212 & 30 & 287 & 62 & 265 & 36 & 363 & 32 & 200 & 40 & 272 & 43 & 324 & 25 & 392 \\
\hline $16: 30$ & 52 & 157 & 20 & 229 & 55 & 243 & 49 & 347 & 42 & 226 & 34 & 302 & 53 & 350 & 22 & 425 \\
\hline $16: 45$ & 53 & 174 & 12 & 239 & 69 & 290 & 37 & 396 & 35 & 207 & 51 & 293 & 53 & 358 & 18 & 429 \\
\hline $17: 00$ & 53 & 209 & 26 & 288 & 59 & 224 & 39 & 322 & 34 & 220 & 27 & 281 & 62 & 353 & 24 & 439 \\
\hline $17: 15$ & 39 & 164 & 26 & 229 & 51 & 285 & 42 & 378 & 27 & 219 & 36 & 282 & 45 & 348 & 24 & 417 \\
\hline $17: 30$ & 49 & 180 & 27 & 256 & 41 & 264 & 36 & 341 & 46 & 217 & 47 & 310 & 43 & 338 & 26 & 407 \\
\hline $17: 45$ & 42 & 184 & 17 & 243 & 56 & 220 & 42 & 318 & 43 & 226 & 46 & 315 & 33 & 365 & 23 & 421 \\
\hline $\begin{array}{l}\text { Grand } \\
\text { Total }\end{array}$ & 385 & 1441 & 181 & 2007 & 446 & 2053 & 331 & 2830 & 283 & 1726 & 313 & 2322 & 383 & 2791 & 197 & 3371 \\
\hline
\end{tabular}

Speed information was collected for all buses on the days of interest for four approaches (i.e.

two westbound and two eastbound approaches) over two intersections in $50 \mathrm{ft}$. increments (i.e. 50, 100, $150, \ldots$, and $750 \mathrm{ft}$. back from the intersection). The average speed at each location, broken up by time of day was calculated to perform a quantitative congestion analysis to compare the impact of the intersection geometries of the two westbound approaches and the two eastbound approaches. The intersection geometries are shown in Figure 2. 


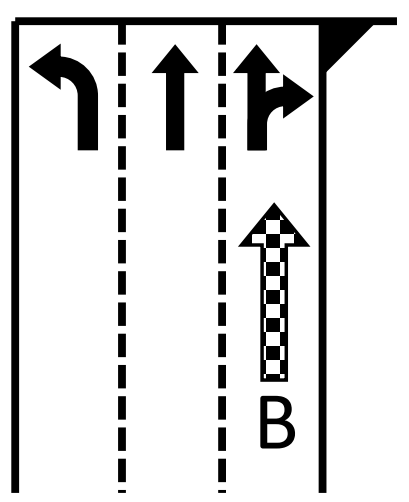

(a)

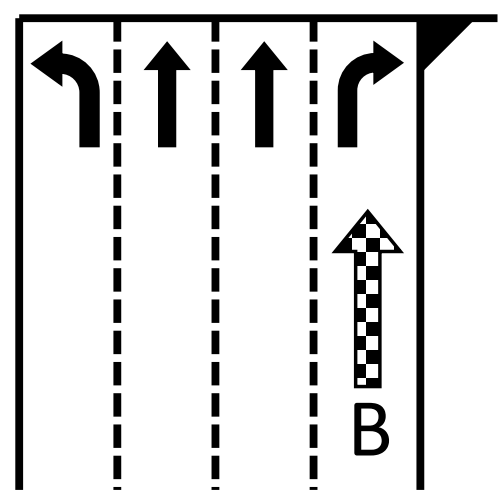

(b)

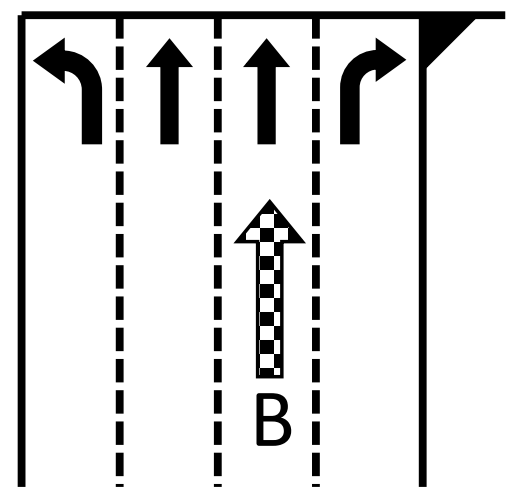

(c)

Figure 2 - Intersection geometries with the bus travel lane indicated with an additional arrow (these lanes are not exclusive to buses): (a) westbound approach to $82 \mathrm{nd}$ (b) eastbound approach to $82^{\text {nd }}$ and westbound approach to $39^{\text {th }}$ (c) eastbound approach to $39^{\text {th }}$.

\section{Literature Review}

The Tri-County Metropolitan Transportation District of Oregon (TriMet) has been archiving automatic vehicle location (AVL) and automatic passenger count (APC) data for all bus trips at the stop level since 1997 as part of their bus dispatch system (BDS). Since introduction of AVL/APC data, researchers have studied factors affecting bus travel time and service reliability at the route level [7] [8], stop-to-stop segment level [9], and the time-point segment level [10] [11] [12]. The route level encompasses an entire bus route from its first stop to its last; the stop-to-stop segment level uses geolocation information to examine bus behavior between 4000 stops; the time-point segment level examines the bus route dynamics between two scheduled bus stops (e.g. bus schedules are written to time points). Additionally, researchers have analyzed archived bus data statistically for travel-time delay, deviation, and coefficient of variation [11] [13] [14] [15] [16].

Researchers examining public transportation systems are generally agreed on the key factors affecting travel time: trip distance, number of bus-stops, road geometry, signalized intersections, time of day, passenger movements, and weather. These studies help provide performance metrics guiding decisions about possible changes to transit policy, bus-stops locations, bus routes, and signal timing. 
Several studies have also investigated the impact of signalized intersections on bus travel time [9] [12] [14]. For example, bus bunching, a situation where two buses are traveling the same route one after another, can affect the speed of buses, especially the follower [12]. The integration of signal phase and traffic data at the stop-to-stop level has shown that the red time, proportion of red-time per cycle, bus-stop locations, and traffic volumes are significant factors affecting bus-stop-to-stop travel time variability [2].

Beyond performance metrics of the bus system, buses have been used as probes to estimate travel times for the rest of traffic [17]. In particular, researchers have used TriMet buses as probe vehicles to evaluate arterial and transit performance [18]. Prior to 2013, these studies used TriMet stoplevel data, which was all that was available at the time; as such, information between stops was not available. To estimate travel times and trajectories between stops, researchers used non-transit vehicles as proxies or estimated travel time using the recorded/reported maximum speed in a segment between stops [17].

Signal delay is also a key source of variability for bus travel time [2] and is of interest to transit operators and researchers. Studies have looked at the signalized-intersection level and determined that transit signal priority can dramatically improve service reliability [9]. Most recently, researchers used high-resolution time and position information to determine bus travel speeds between bus-stops, categorize speed breakdowns, and identify intersection signal/queuing delays [19]. This higher resolution data removed the need for some educated guesswork when using buses as probes or determining performance metrics between stops.

Until recently, researchers had only examined specific points to determine performance metrics on urban arterials with stop level data. While the most recent congestion analysis did look at a specific intersection [19], no conclusions were drawn about the intersection examined other than a statement that the data could be used for such an analysis. Therefore, a gap in research exists: an in-depth 
intersection analysis to be conducted using high-resolution data. This study will use both stop level and 5-second resolution data provided by TriMet via their Bus Dispatch System to look at specific intersections along a major arterial in Portland, OR. The objective of this paper is to use a congestion analysis to examine how different geometries affect bus travel times at intersections during the weekday commute.

The route chosen for this study, Route 9, runs from NE Kelly \& 5th to NW 6th \& Flanders in Portland, Oregon. Route 9 is an excellent choice for this study due to predictable and known traffic volumes as established by many years of data collection. Additionally, the traffic volume is predictable along its length during the peak hour. This predictability allows for analyses of separate intersections to be compared once adjustments to traffic volume have been applied. The current hypothesis is that intersections with separated right turn lanes will have significantly less congestion than combined through-right lanes for intersections with far-side bus-stops. If confirmed, this hypothesis will indicate to transit authorities a means to improve overall service.

\section{Methodology}

TriMet's Bus Dispatch System (BDS) archives detailed stop level data and 5-second resolution (5SR) data for all buses and trips. The 5-SR data allows for average speeds, separated by time of day, to be calculated for specific locations along a route. Multiple points are then linked to show how average speed changes based on location and time of day. The process of this analysis is outlined below.

\section{Sorting data}

The data, as provided by TriMet, includes operation date, vehicle ID, time, and location (as GPS) for all route 9 buses on all days. The unedited data set is initially sorted by operation date, vehicle ID, and time, in that order. Fridays, Saturdays, Sundays, and Mondays are removed leaving Tuesdays, 
Wednesday, and Thursdays for the first three weeks in November. These three days are treated equally to create a midweek analysis.

Defining the Point of Interest (POI)

The point of interest (POI) is a specific location defined by GPS coordinates; these coordinates are defined by the locations where speed needs to be calculated. Google Earth ${ }^{\mathrm{TM}}$ was used to find coordinates in $50 \mathrm{ft}$. increments upstream of a crosswalk. A total of 15 POI's were defined for each intersection approach and buses will pass through these locations on approach to the intersection. Each of these POIs will be used to extract data needed to calculated speed. The POIs used in this analysis are shown in Figure 3. The POI closest to the crosswalk is the 50ft. POI and the one furthest away is the 750ft. POI. The study area is marked with a dotted red line. There are streets connecting to these segments; however, they are minor, non-through streets that are unlikely to add much delay to the segments. The bus stop prior to the intersection is marked on each map.

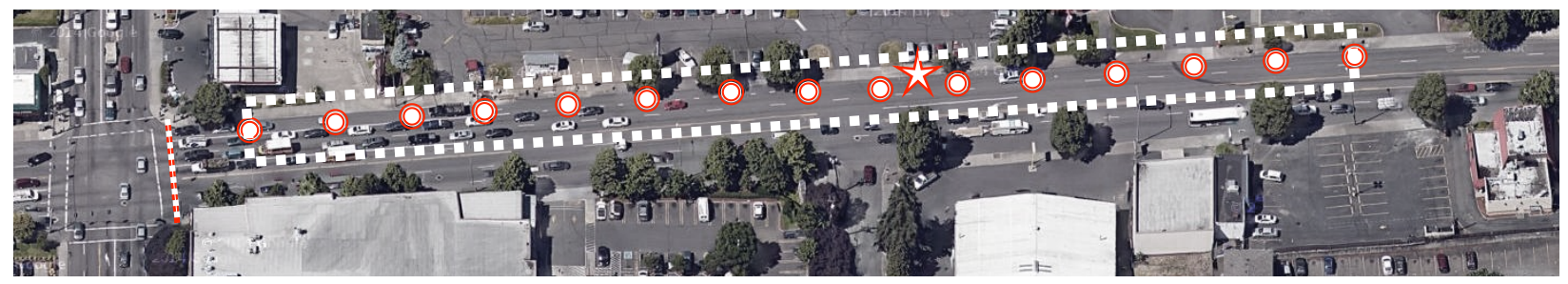

(a) - Bus stop $474 \mathrm{ft}$. from crosswalk

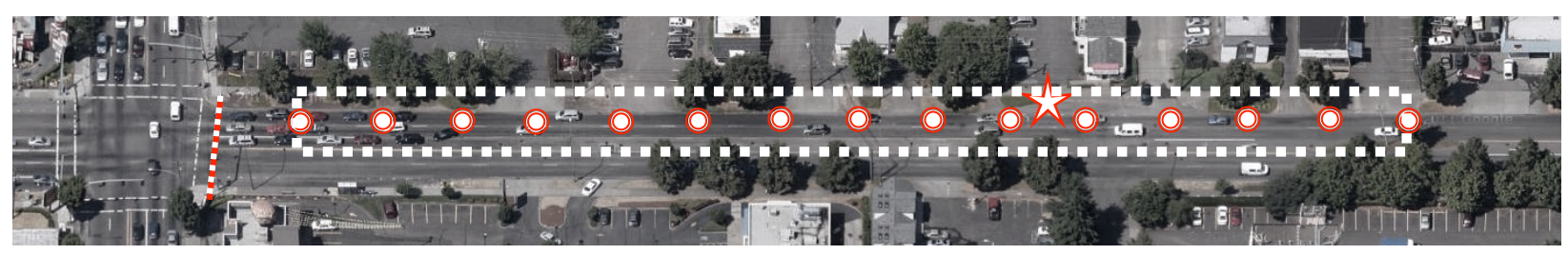

(b) - Bus stop $517 \mathrm{ft}$. from crosswalk 


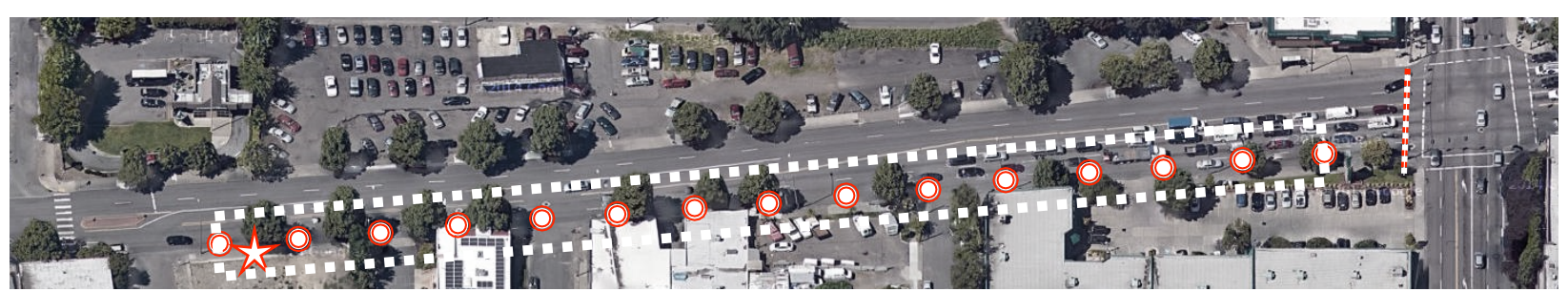

(c) - Bus stop $732 \mathrm{ft}$. from crosswalk

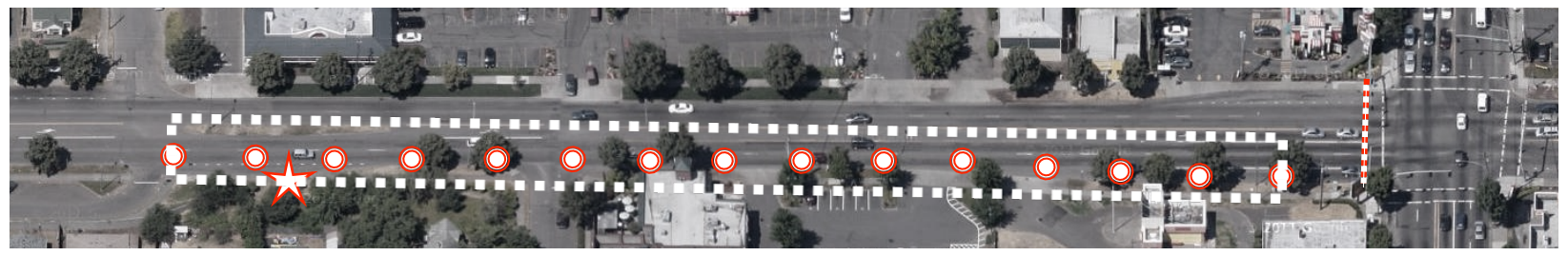

(d) - Bus stop $664 \mathrm{ft}$. from crosswalk

Figure 3 - Satellite photos of the four intersection approaches with the start of intersection marked $\mathrm{red} /$ white dashed line, Study area is marked with red dashed line, POls marked with red/white circles, and bus stop prior to intersection marked with a red/white star. (a) westbound approach of SE $39^{\text {th }}$ Ave. (b) westbound approach to SE $82^{\text {nd }}$ Ave. (c) eastbound approach to SE $39^{\text {th }}$ Ave. (d) eastbound approach to SE $82^{\text {nd }}$ Ave.

\section{Extracting Data around a specific point}

Once a single POI has been defined (e.g. $150 \mathrm{ft}$. west of SE $82^{\text {nd }}$ Ave. on Powell Blvd.), point-pairs nearest to the POI are extracted to form a new data set. Each point-pair must be a set of consecutive points from the same bus where one point is upstream and one point is downstream of the POI. These consecutive points are then used to estimate speed at the POI. While point-pairs for consecutive POIs may overlap, they still produce an adequate average speed at a specific location. An example is provided for finding the point-pairs on a westbound trip.

\section{Finding Points East of POI}

Four criteria are used to find points of a westbound trip.

i. The distance from any point to the POI is less than a specified range. Average distances between each set of consecutive points in the original data is about $150 \mathrm{ft}$. The standard deviation of the distances is about $100 \mathrm{ft}$. Therefore, the range specified was $500 \mathrm{ft}$. This captures approximately 
$99.9 \%$ of all buses around a point as $500 \mathrm{ft}$. is 3.5 standard deviations above the mean. While it is not possible for a bus to travel the full $500 \mathrm{ft}$. in 5 seconds on this segment, it would not be unrealistic to see this distance when the time difference between archived data points is inbetween 10 or 15 seconds. This specified range also serves to limit points that are on parallel streets even if they have a point east and west of the POI. While the points surrounding a specific $\mathrm{POI}$ may overlap with the next $\mathrm{POI}$, each point-pair remains centered around a specific POI creating unique speed profiles for each.

ii. The distance from a point that meets criteria i. to the POI is at a minimum distance east of the POI when compared to other consecutive points in the original data. Sometimes, several consecutive points are east of the $\mathrm{POI}$ and are within the specified range. Criteria ii. ensures that only one of those points is selected and that it is the point closest to the POI.

iii. The vehicle must be traveling west before and after this point for at least the full $750 \mathrm{ft}$. range of analysis. If a bus turned at the intersection, it would not be included in analysis.

iv. The time associated with the GPS coordinates are within the specified range. For this study, 4:00 a.m to $12: 00 \mathrm{pm}$ was used.

Each point of the original data set is compared to the POI to determine four criteria in the order provided. If a point from the ordered original data meets the first criteria, it goes onto the second.

\section{Extracting critical points}

If all four criteria are met, then that point along with the next consecutive point is marked for extraction. This process, when applied to the entire original data set, produces a new data set of pointpairs with one point directly east and one point directly west of a POI. The process is repeated with an unedited data set for each new POI. A sample piece of this data is provided in Table 2. 
Table 2 - A sample piece of extracted data. The POI is for westbound travel, $150 \mathrm{ft}$. upstream of the crosswalk of $82^{\text {nd }}$ (GPS: $45.497470 \mathrm{~N},-122.577938 \mathrm{E}$ ). The point-pairs are banded together. Each pointpair were from the same day and vehicle, were consecutive, and have one point east and one point west of the POI.

\begin{tabular}{ccccc}
\hline Operation Date & Vehicle ID & Seconds Past Midnight & Latitude & Longitude \\
\hline 4-Nov-14 & 2007 & 80722 & 45.4974767 & -122.5775900 \\
4-Nov-14 & 2007 & 80727 & 45.4974800 & -122.5780217 \\
4-Nov-14 & 2015 & 27876 & 45.4974867 & -122.5777983 \\
4-Nov-14 & 2015 & 27881 & 45.4974833 & -122.5780850 \\
4-Nov-14 & 2153 & 59767 & 45.4974633 & -122.5777917 \\
4-Nov-14 & 2153 & 59772 & 45.4974650 & -122.5779500 \\
4-Nov-14 & 2206 & 27667 & 45.4974733 & -122.5777550 \\
4-Nov-14 & 2206 & 27672 & 45.4974750 & -122.5781750 \\
4-Nov-14 & 2222 & 27661 & 45.4974783 & -122.5775983 \\
4-Nov-14 & 2222 & 27666 & 45.4974800 & -122.5779550 \\
\hline
\end{tabular}

This process can be used for any straight roads with known GPS coordinates. For eastbound traffic, the analysis was completed for points west first. For traffic moving northwest, although not done in this study, extraction would begin with points southeast of the POI.

Figure 4 shows the spread of point-pairs for two POls on westbound approach to SE $82^{\text {nd }}$ Ave. The plot contains November 4-6, 11-13, and 18-20. The $x$-axis shows distance from the POI. Direction of travel is from left to right. The $y$-axis is the number of observations at each distance grouping. Figure 4 also shows a box and whisker plot for the data surrounding each POI. $50 \%$ of points are contained within the boxes and the whiskers denote the lesser of \pm 1.5 times the range of boxes or point furthest from POI. These box and whisker plots were created for all 15 POls for this approach and are shown in Figure 5. On Figure $4 b$, the spike in number of observations between $60<x \leq 100$ is due to a bus stop that lies at $520 \mathrm{ft}$. before the SE Powell and $82^{\text {nd }}$ intersection in the westbound direction. There are an equal number of observations on either side of each POI. 


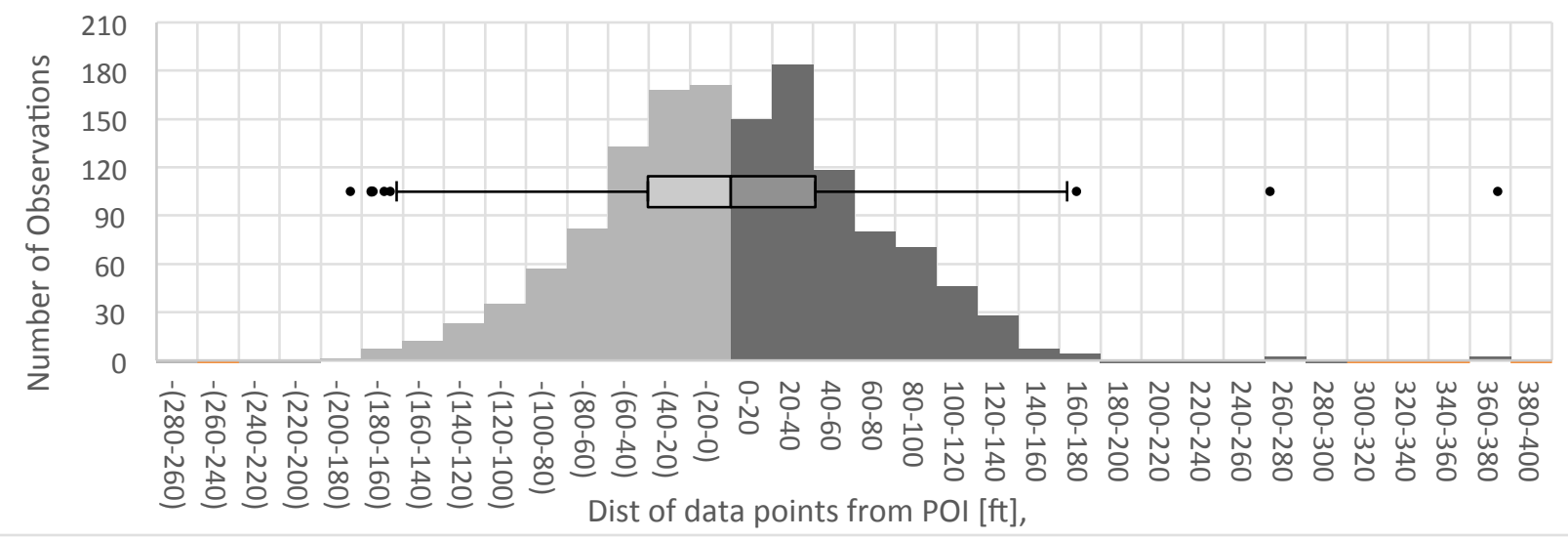

(a)

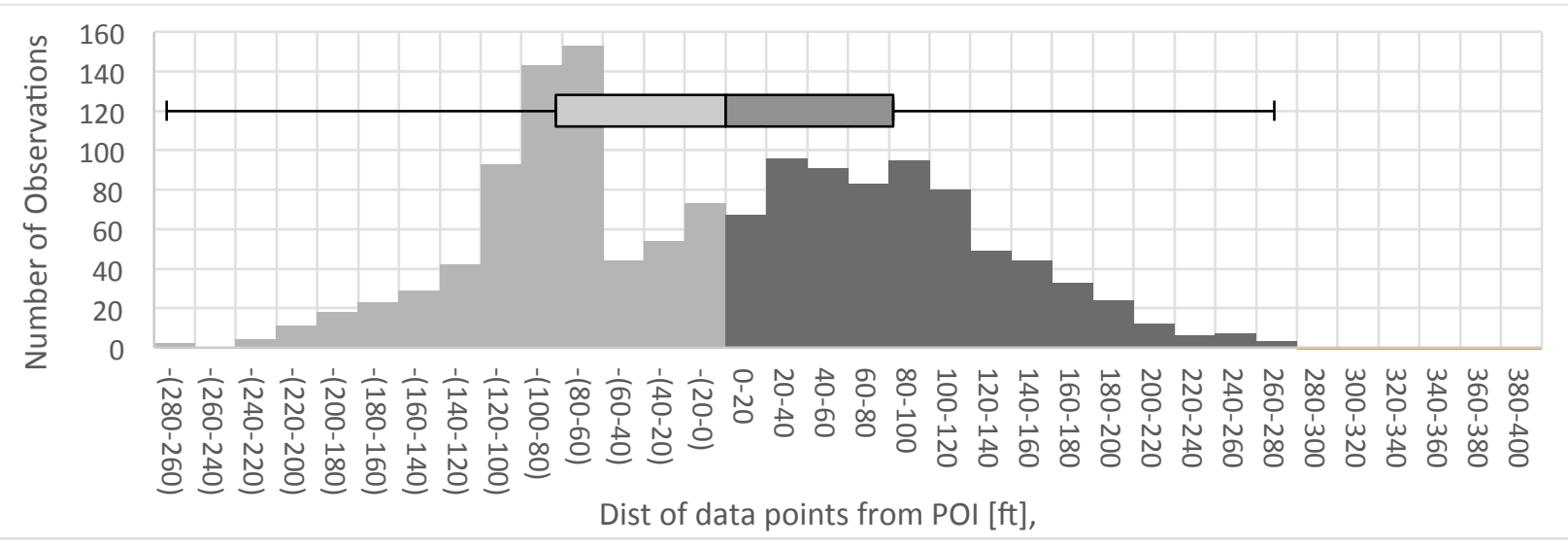

(b)

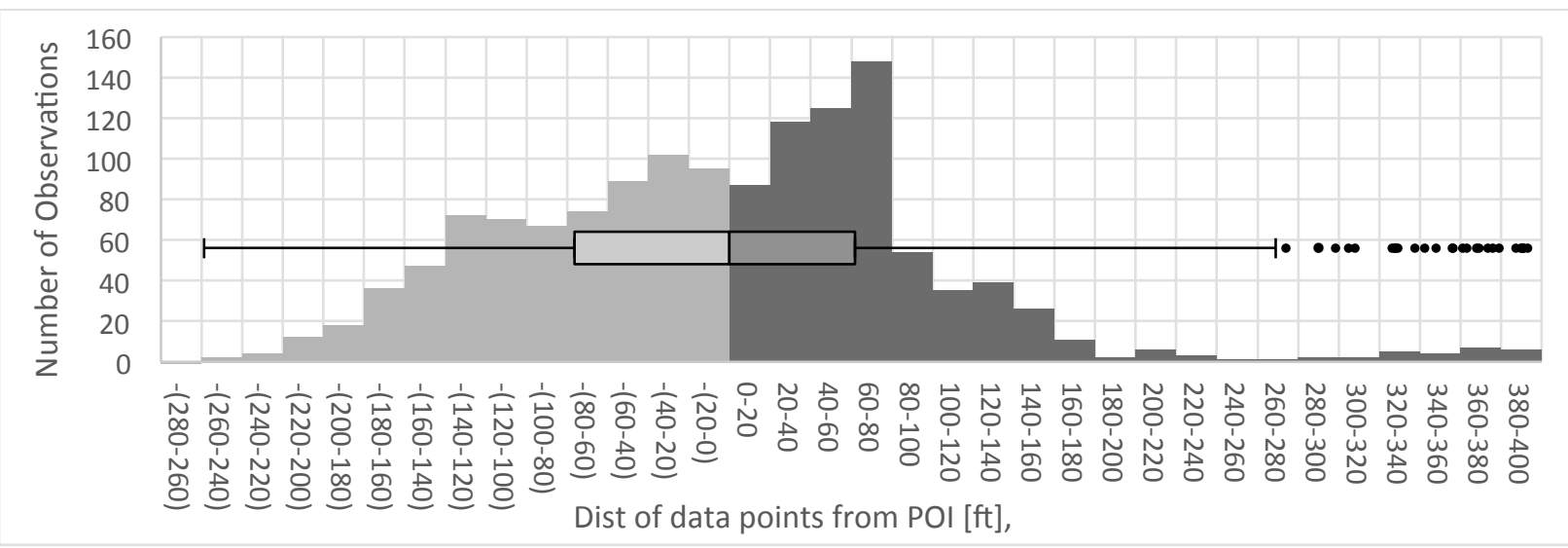

(c)

Figure 4- histogram and box and whisker equivalent for data point spread around points of interest for westbound approach to SE $82^{\text {nd }}$ Ave on Powell Blvd, (a) POI = 50ft. upstream of crosswalk, (b) $450 \mathrm{ft}$. upstream of crosswalk, \& (c) $600 \mathrm{ft}$. upstream of crosswalk. (a), (b), \& (c) $n_{\text {total }}=1378, n_{\text {point-pairs }}=689$.

For each approach to an intersection, 15 POls were used to define the average speed curve, with each calculation done at a single POI. The statistical distribution is shown in Figure 5 using a box 
and whisker plot for all POIs along one approach shown in Figure 3a. The set of data used in the creation of Figure 5 is one of four final sets; one was created for each westbound and eastbound approaches to SE $82^{\text {nd }}$ Ave. and SE $39^{\text {th }}$ Ave. along Powell Blvd.

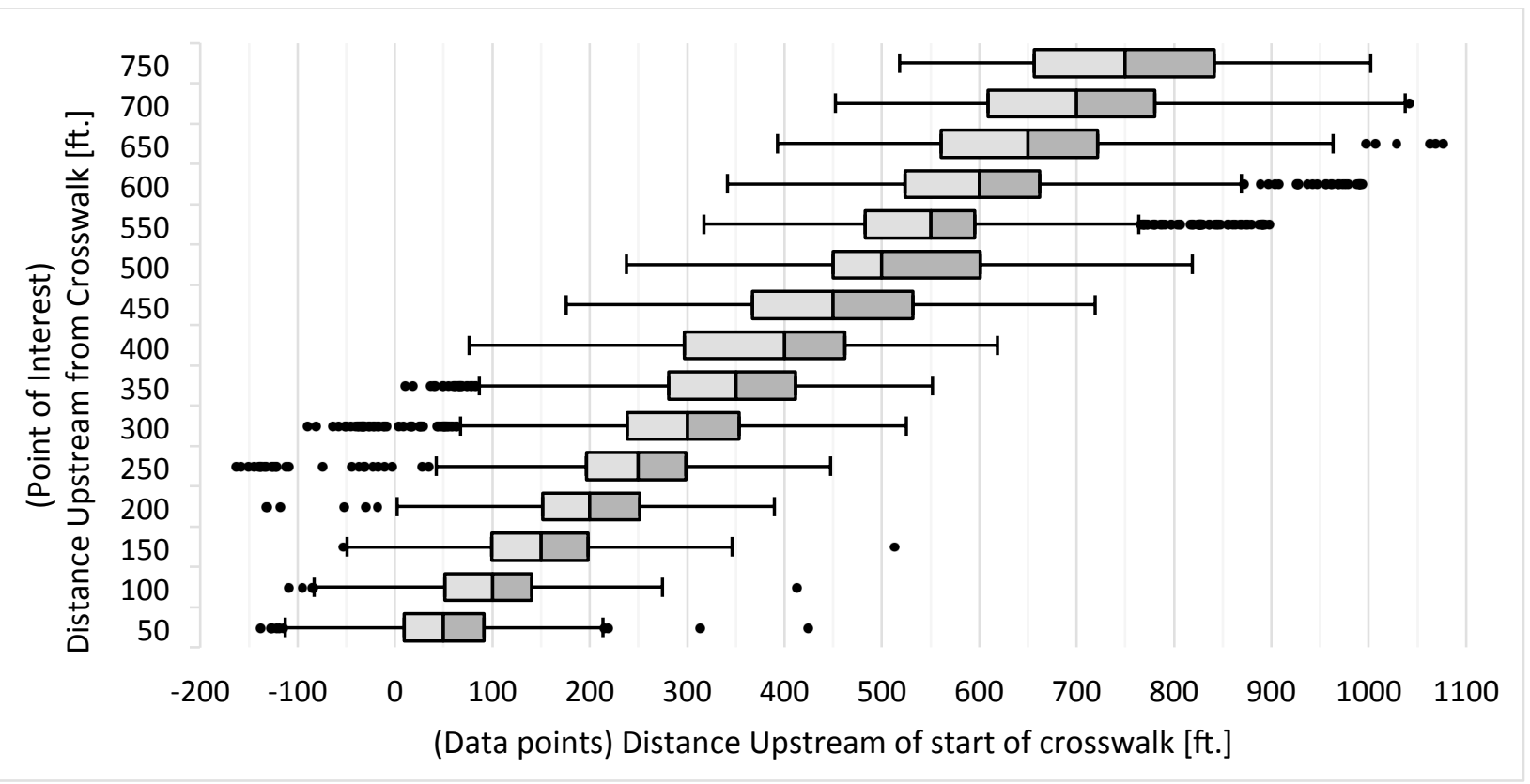

Figure 5 - Spread of 5-SR point-pairs around all POIs on approach to SE $82^{\text {nd }}$ Ave. Each point-pair has one point before its $\mathrm{POI}$, one after. Light and dark grey boxes show $25 \%$ of points each, whiskers denote the lesser of \pm 1.5 times range of grey boxes or maximum distance from POI, and outliers are shown. POI$1.13 \mathrm{ft}<$ median $<$ POI+0.58 ft, $\mathrm{n}_{\text {total }}=20,662$ (10,331 point-pairs), $\mathrm{n}_{\text {mode }}=689$ point-pairs, $\mathrm{n}_{\text {outlier }}=95$ $(0.46 \%)$

\section{Calculate average speed using a moving average}

Average speed is calculated for each POI using its extracted point-pairs. The change in distance between each point in a pair was calculated and then divided by the change in time between those points. Next, the day was divided into intervals. All buses that reported a speed were sorted by the time of day into one of these boxes. In the event that two buses passed within the same 1-minute interval, a weighted average was calculated. In the 2014 paper by Glick et al., an example is provided of how to obtain this weighted-average speed. 
If three buses report speeds for the same [...] segment of $22.5 \mathrm{mph}, 9.0 \mathrm{mph}$, and 1.4 mph maintained for 4 seconds, 10 seconds, and 64 seconds, respectively, a weight of 4 , 10 , and 64 is assigned to each, respectively. The weighted average speed for that segment would be $3.46 \mathrm{mph}[19]$.

Initially 15-minute and 10-minute averages were created to see trends throughout the day. Figure 6 shows the curves created from this analysis. Little information about traffic trends are visible due to the rapid fluctuations of average speed at each location.

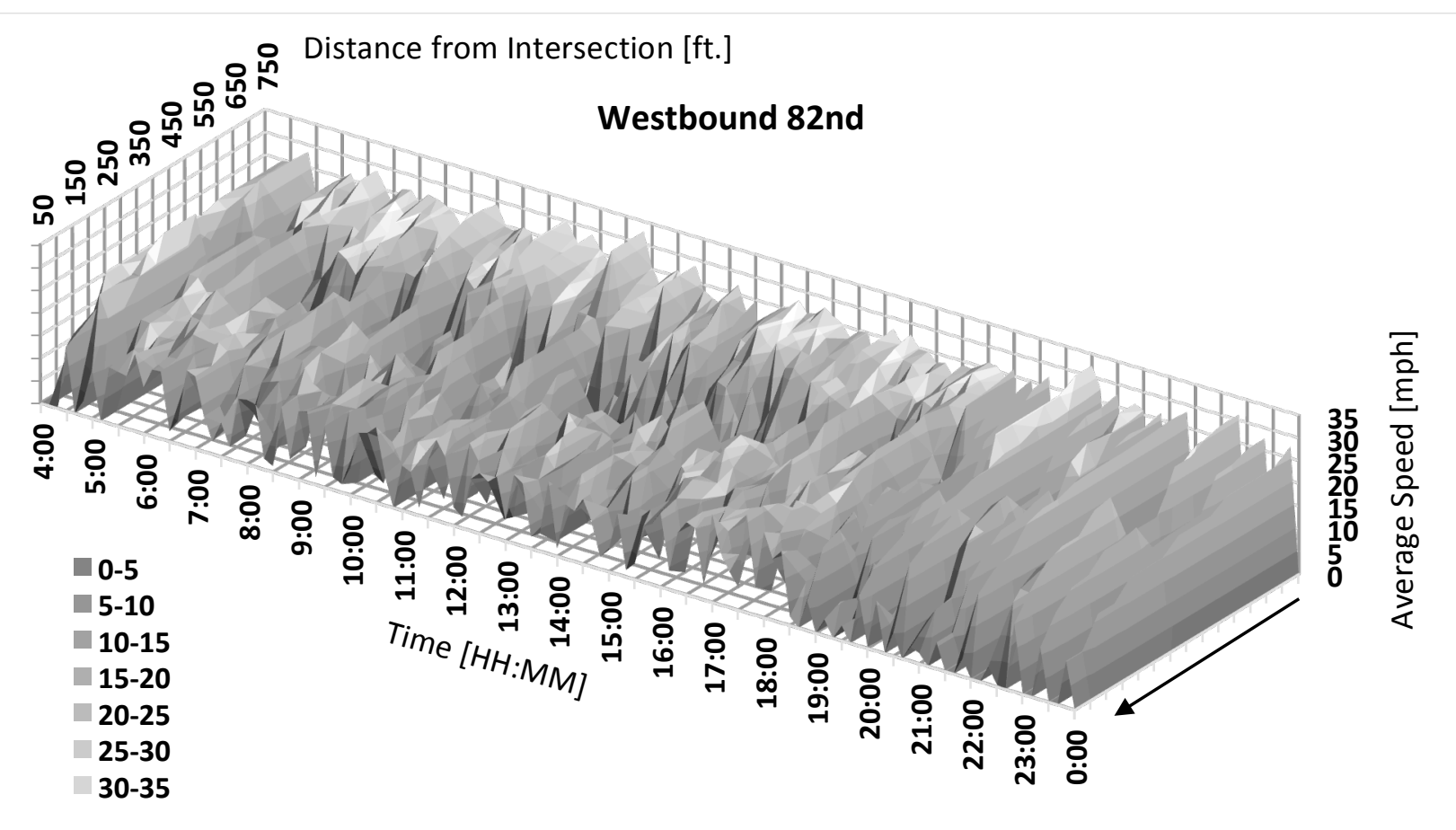

(a) 


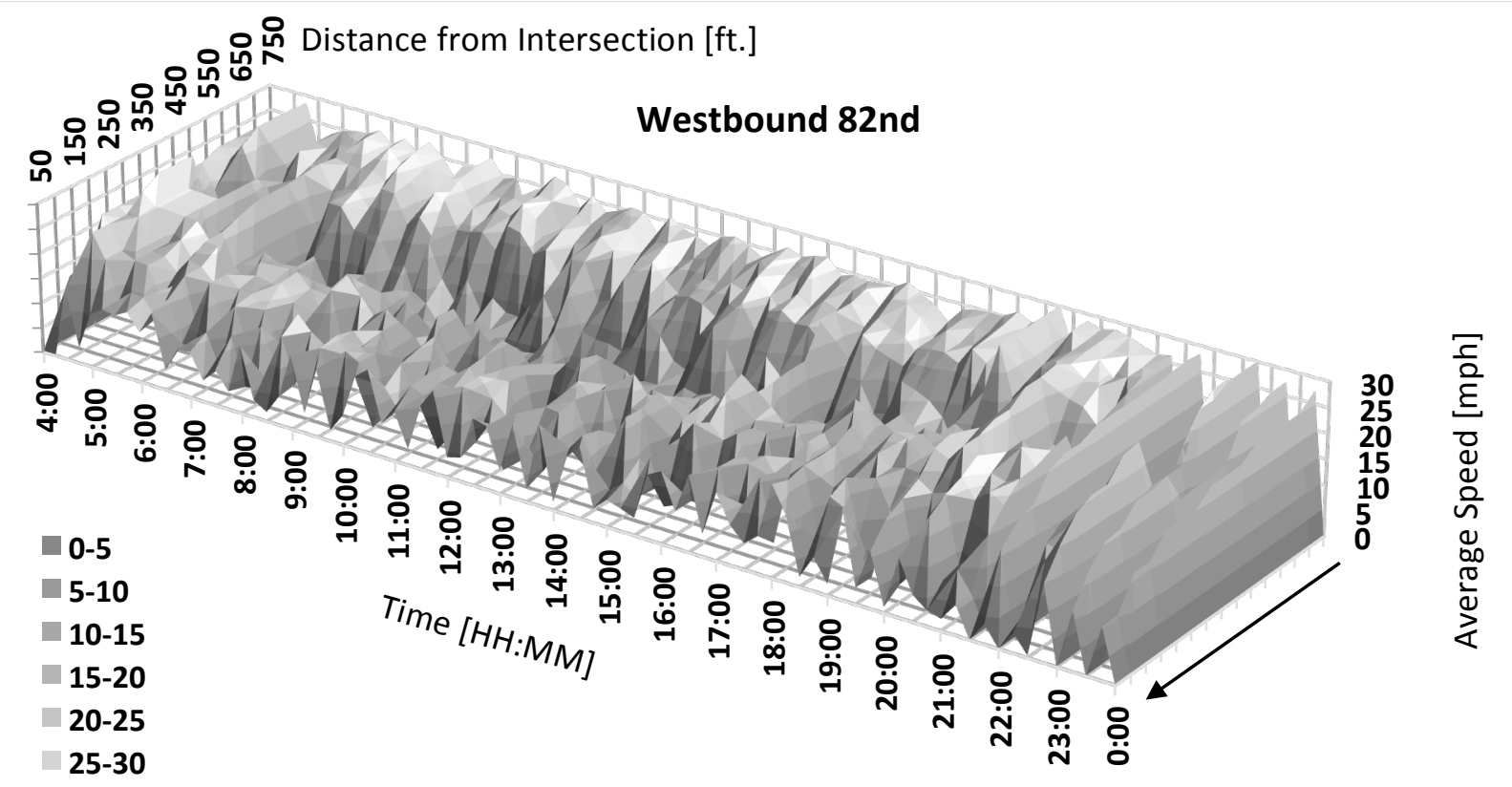

(b)

Figure 6 - Average speed, without moving averages, for westbound approach to SE $82^{\text {nd }}$ Ave. for intervals of (a) 10-minutes and (b) 15-minutes

The information visible in Figure 6 does not convey enough information to be useful. As such, a moving average of $\pm 1, \pm 2, \pm 3$ intervals was applied to the 10 -minute and 15 -minute averages. The best results were obtained from a \pm 30 minute moving average with 10 -minute intervals and \pm 45 minute moving average with 15-minute intervals. Both options are shown in Figure 7; Figure 7b has less variation than Figure 7a likely due to the wider range for the moving average. 


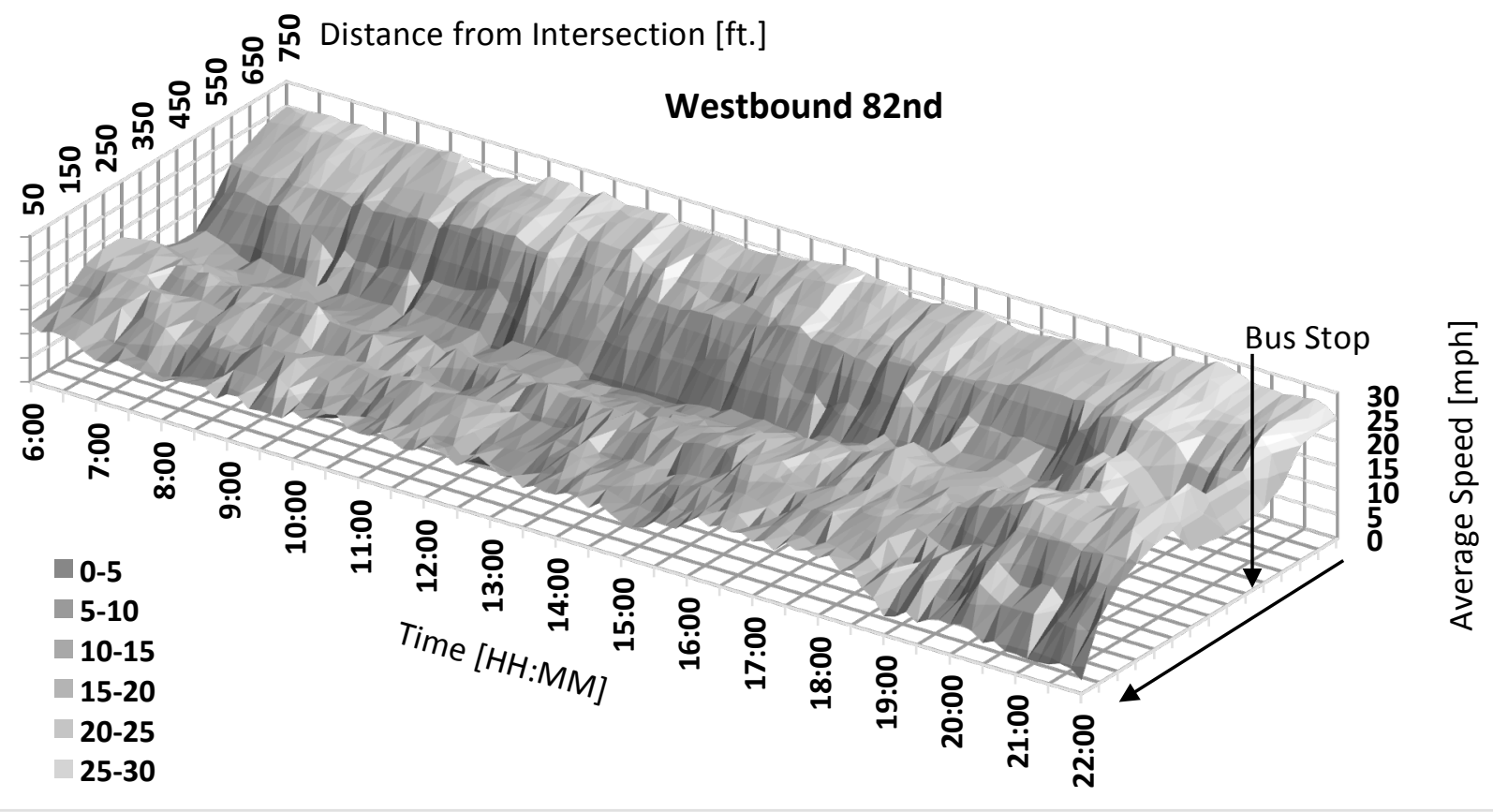

(a)

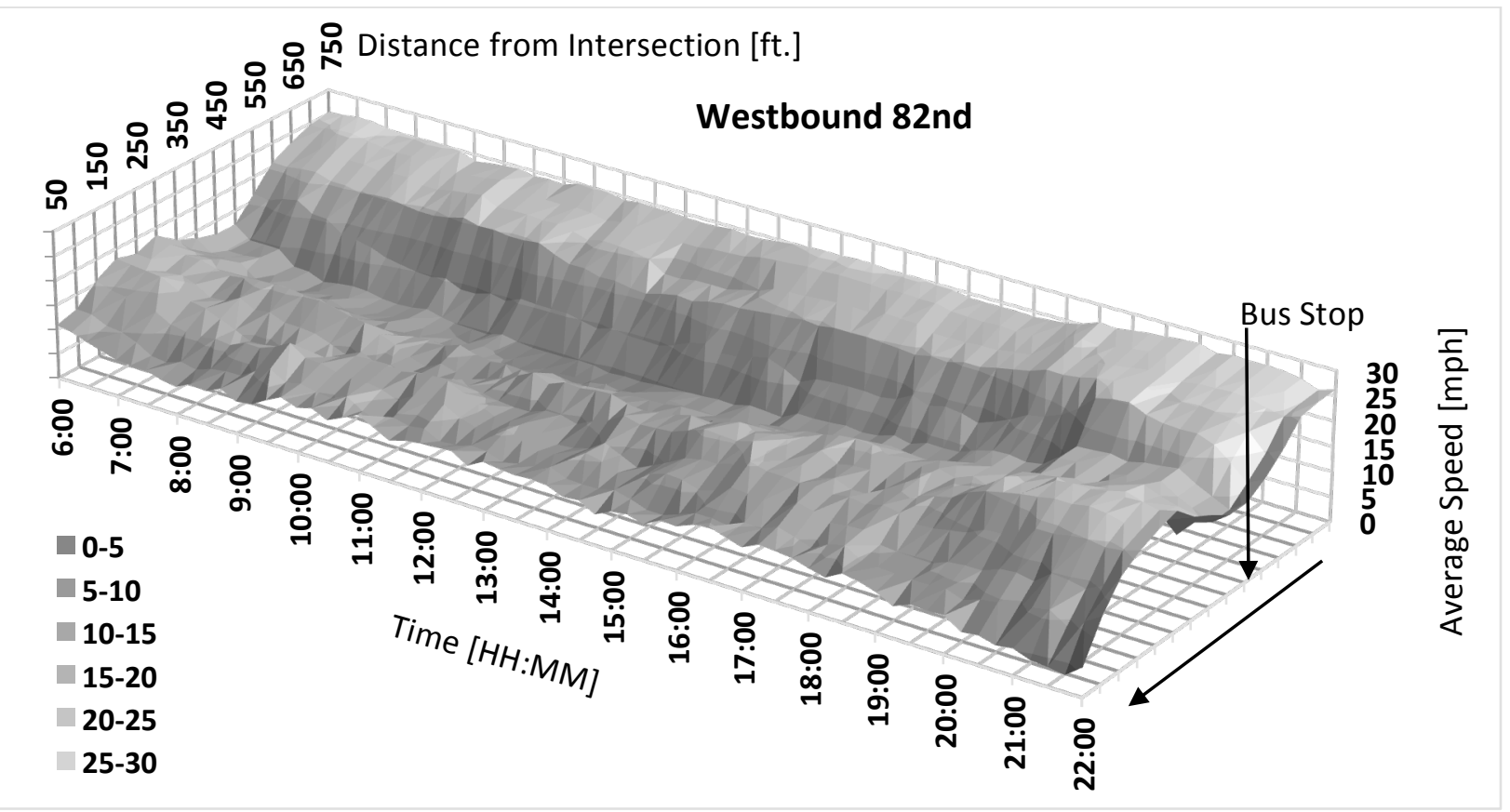

(b)

Figure 7 - Best ranges for moving averages for westbound approach to SE $82^{\text {nd }}$ Ave. (a) \pm 30 minute moving average with 10 minutes intervals ( 7 intervals total). (b) \pm 45 minutes moving average with 15 minute intervals ( 7 intervals total) 
This range, \pm 45 minutes was then applied to data sets with decreasing intervals for the moving average down through intervals of one minute. The trends visible in Figure $7 \mathrm{~b}$ were also visible with decreasing intervals; as such, a moving average was calculated from 45 1-minute intervals before and after each central interval. This created a 1.5 hour moving average with 1 minute resolution.

Once plotted on a 2D graph as shown in Figure 8a, more detailed trends become visible.

However, noise in the plots made visualizing trends upstream of an intersection difficult. To correct this, an additional 5-minute moving average was applied to the final plots and is shown in Figure $8 \mathrm{~b}$. This did not change any of the trends visible in the final plot, but made viewing the data clearer.

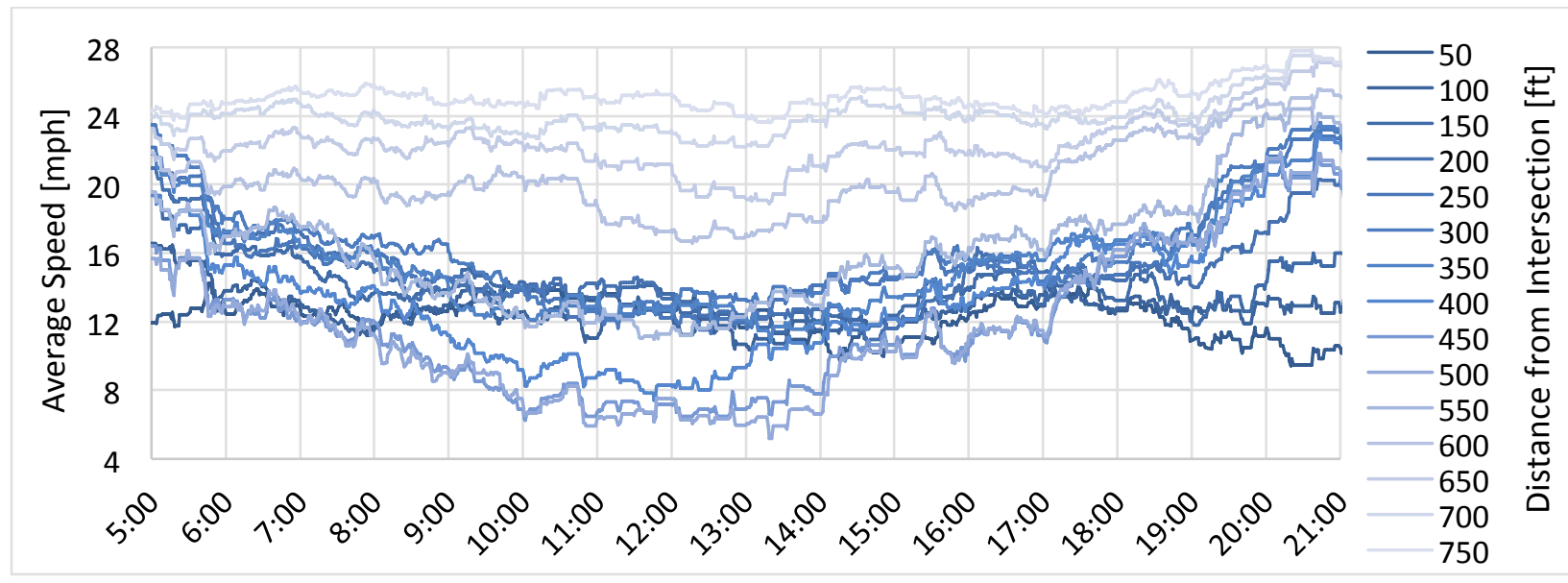

(a)

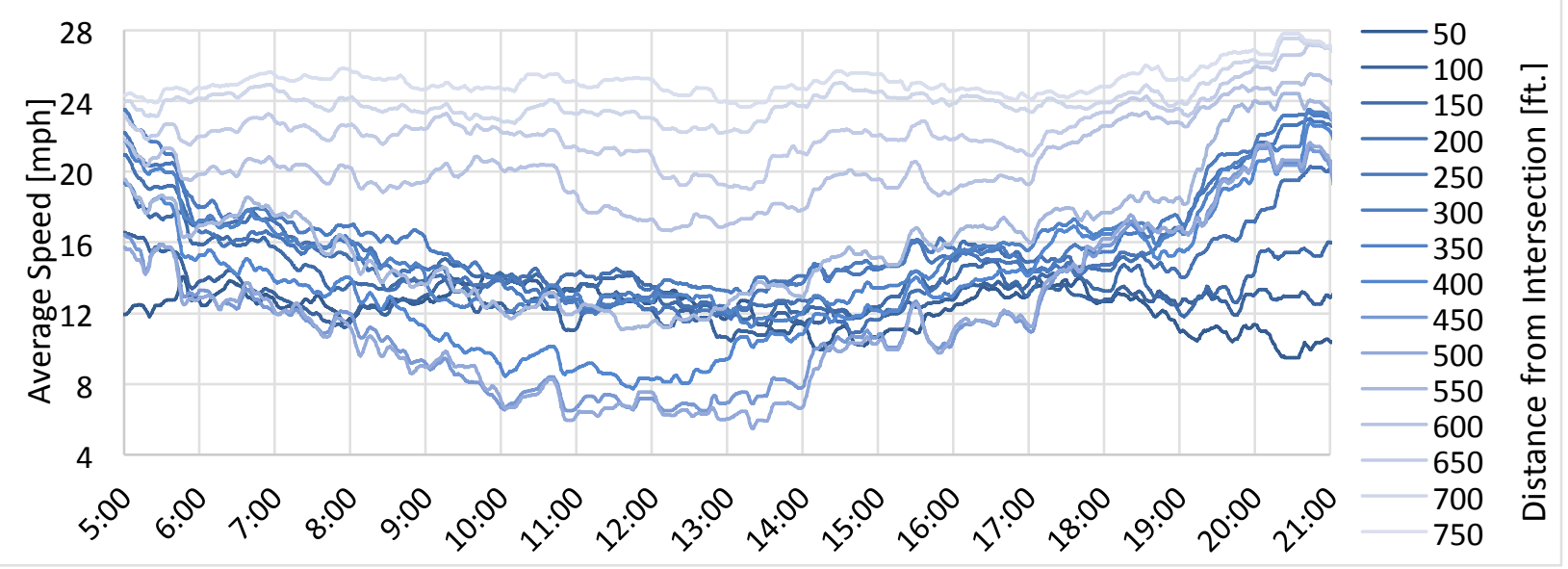

(b)

Figure 8 - Moving average speed on approach to SE $82^{\text {nd }}$ Ave. in the westbound direction. Figure 3(a) shows the results before the additional 5-minute moving average; Figure 3(b) shows after. 


\section{Visualizing the Data}

Figure 9 is an example of a 3D plots that use time of day and distance from the intersection as independent variables. Figure 9 shows speed trends over a full day at all $700 \mathrm{ft}$. of the study area.

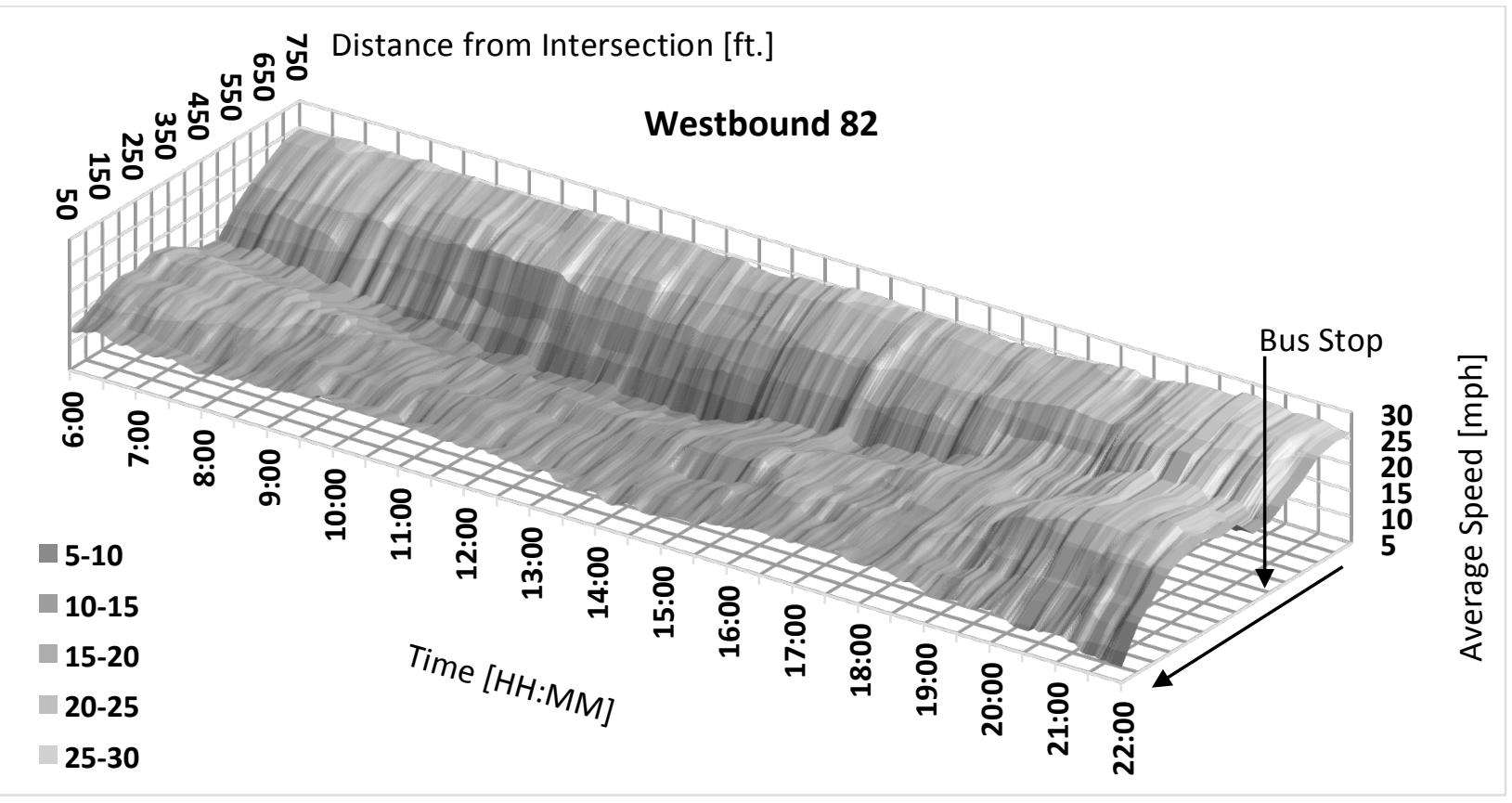

(a) Powell and $82^{\text {nd }}$ Ave. - Westbound Direction

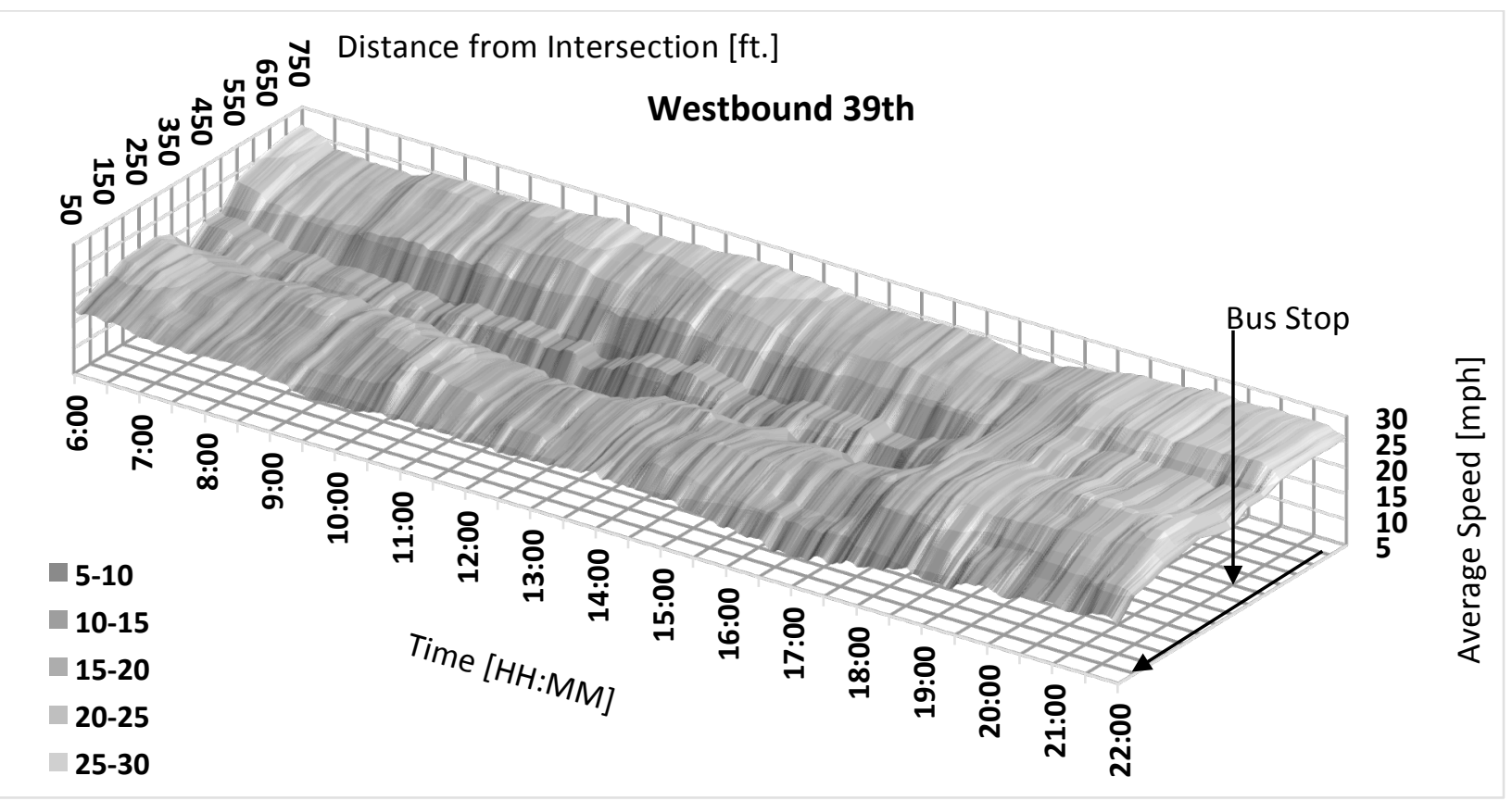

(b) Powell and $39^{\text {th }}$ Ave. - Westbound Direction 


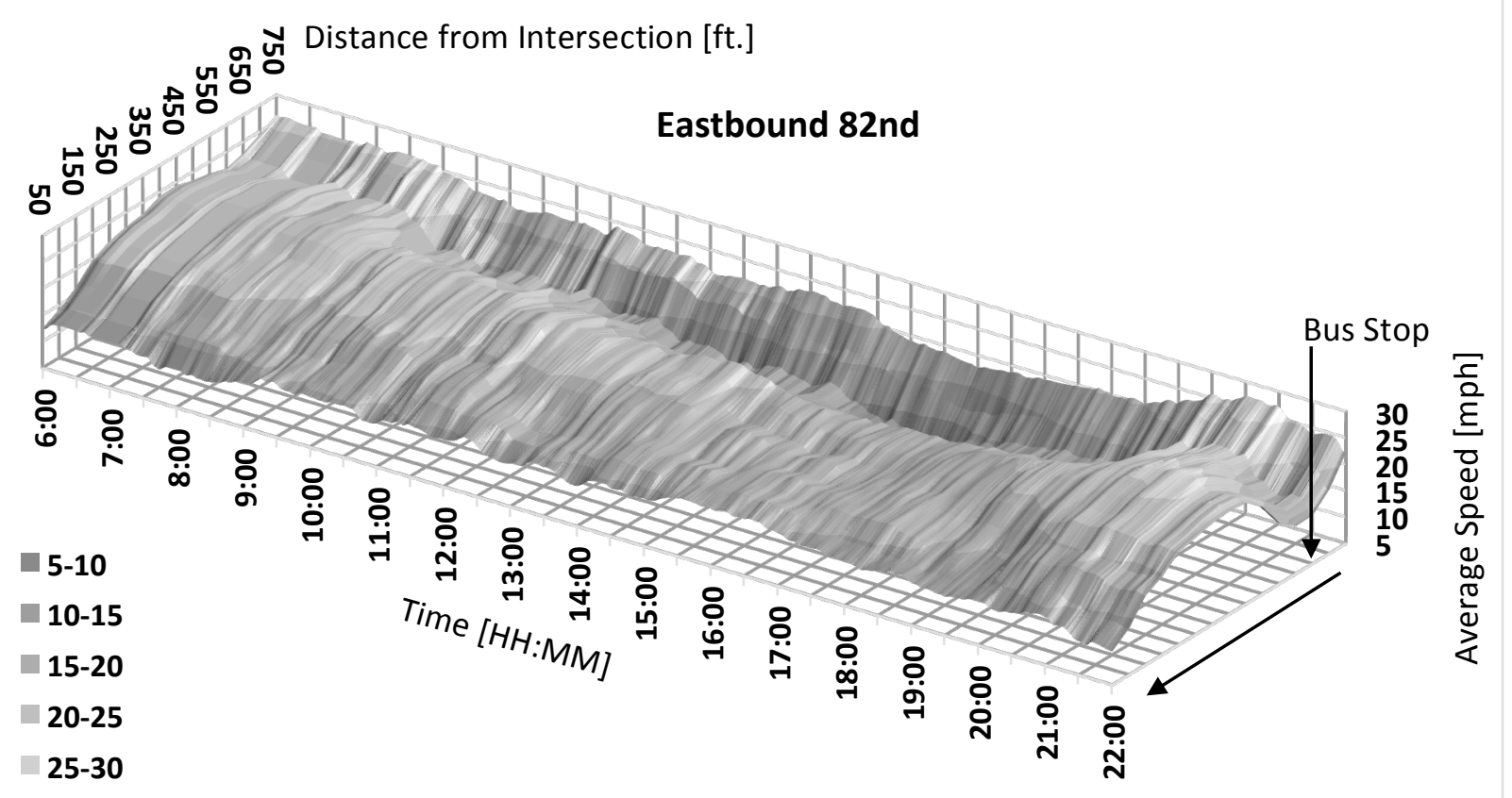

(c) Powell and $82^{\text {nd }}$ Ave. - Eastbound Direction

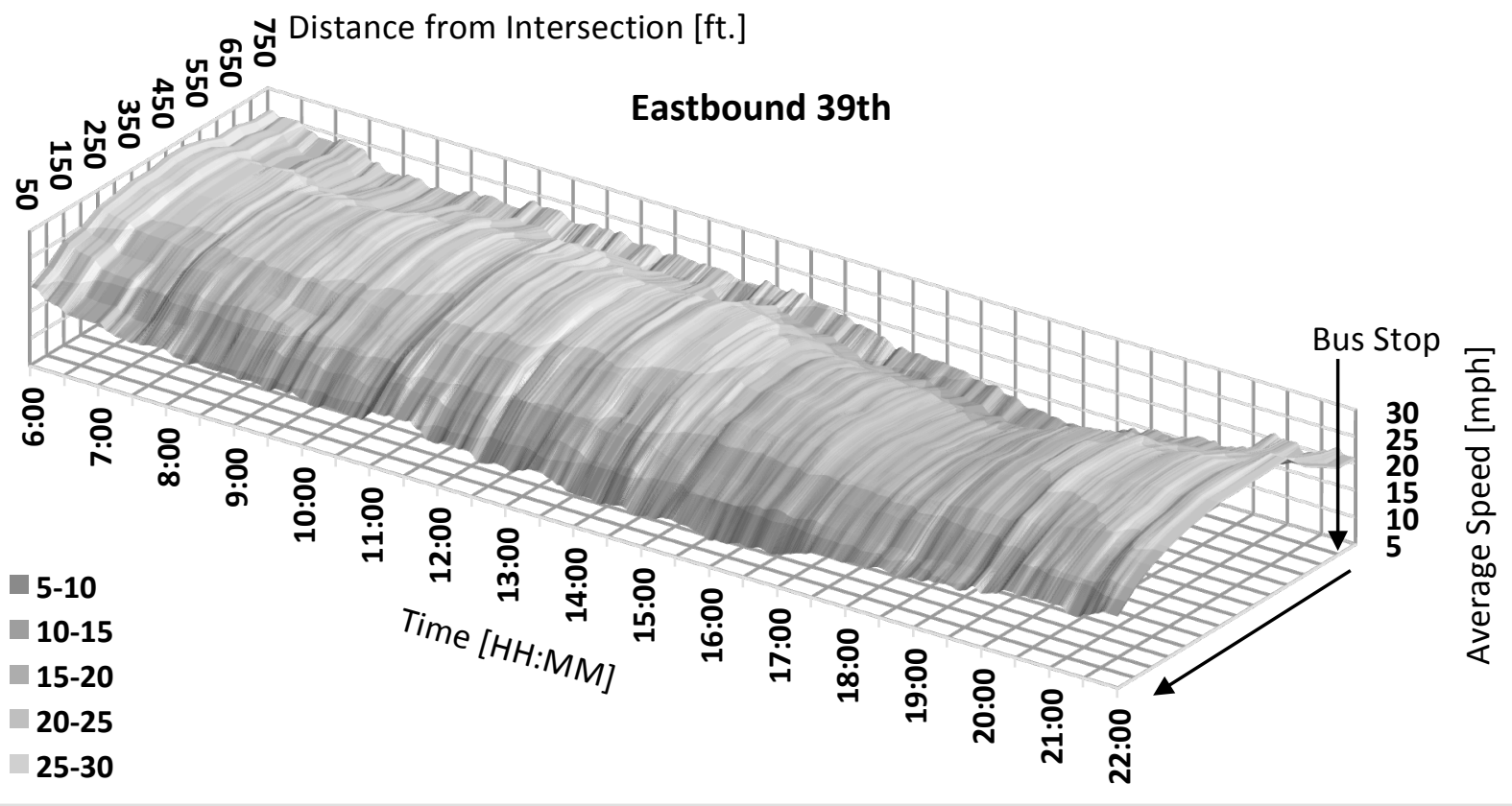

(d) Powell and $39^{\text {th }}$ Ave. - Eastbound Direction

Figure 9 - Average speed of buses on approach to each intersection defined by time of day and distance from intersection. Direction of Travel is indicated by an arrow and the location of each bus stop prior to the intersection is shown with another arrow pointed down towards the distance axis. 
Two major patterns emerge from the Figure 9 plots. First, average bus speed decreased dramatically as buses approach a bus stop, then increase and decrease in-between that bus stop and the intersection. Second, the westbound travel and eastbound travel have different patterns of speed congestion. Due to these differences the congestion was compared separately for each of these two directions of travel.

\section{Quantifying Congestion}

The curves in Figure 9 show the actual travel speed at different times of day and at different distances from the intersection. To quantify how much congestion is being experienced at these locations, the difference in free-flow travel time and actual travel time was used. The free-flow travel speed is a function of distance from the intersection and is defined by an average speed for each $50 \mathrm{ft}$. increment over one hour. For westbound and eastbound travel, the free-flow speed was defined as the average speed between 11:00-12:00 p.m. and 5:00-6:00 a.m., respectively. The calculated free flow travel speeds is shown in Figure 10. Since each average speed is for discrete $50 \mathrm{ft}$. intervals, the distance traveled ( $50 \mathrm{ft}$ ) was divided by speed to get a travel time. The difference between the actual travel time and this free-flow travel time resulted in seconds of delay for each discrete interval. The delay calculated at the Powell and $82^{\text {nd }}$ intersection was multiplied by 1.15 to account for the $15 \%$ lower traffic volume at $82^{\text {nd }}$ then at $39^{\text {th }}[5][6]$ (Table 1). The results of this analysis are shown in Figure 11.

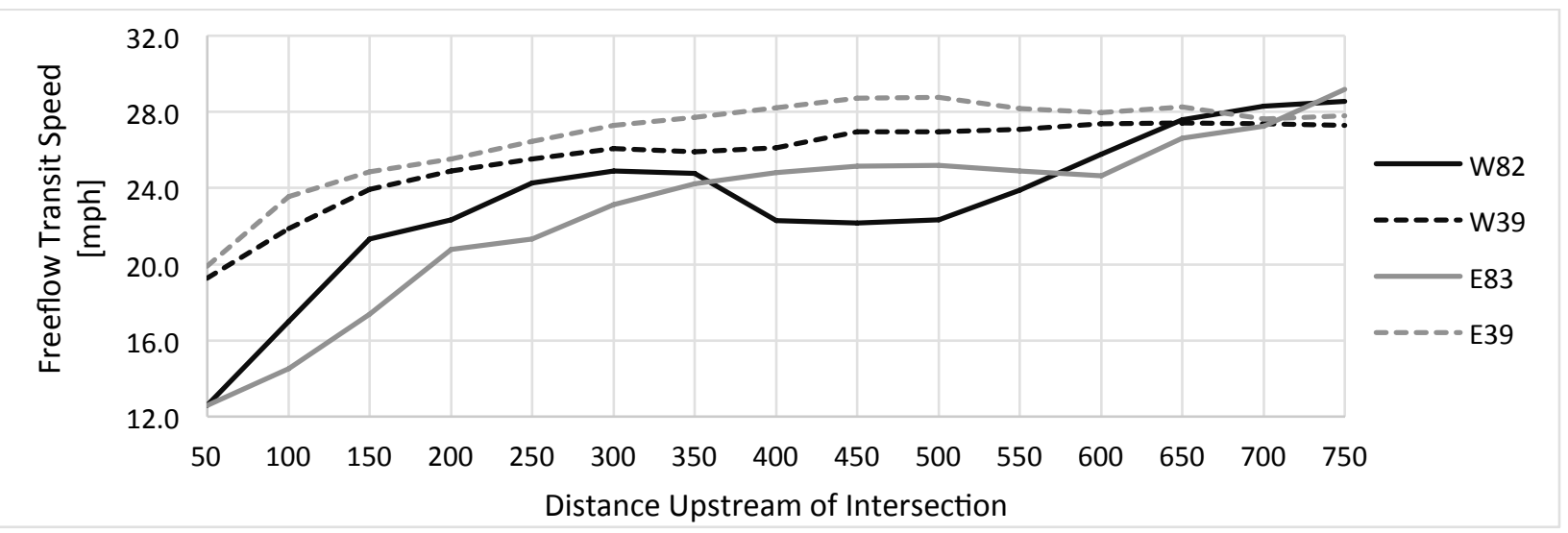

Figure 10 - Free flow Travel Speeds as a function of Distance 


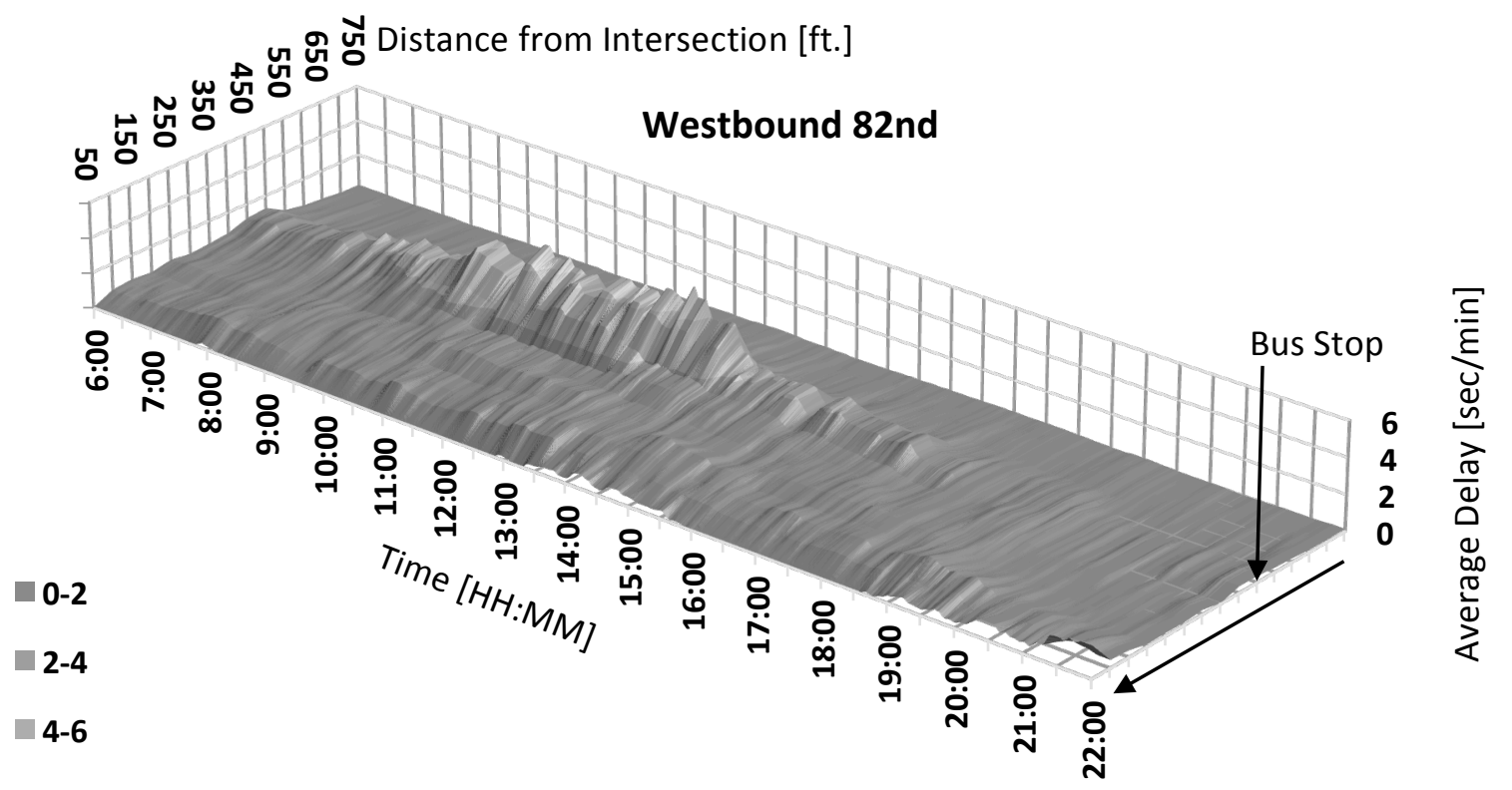

(a)

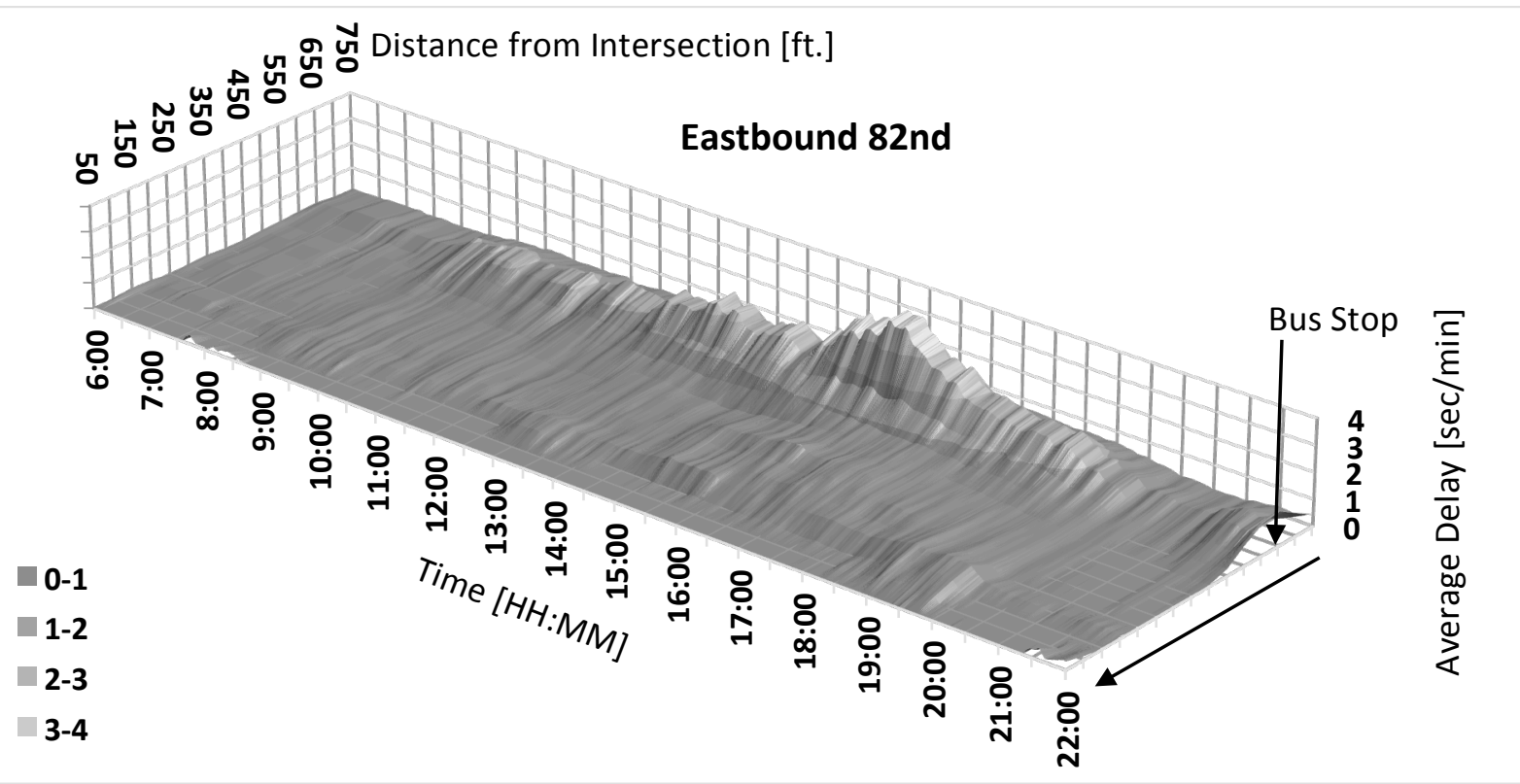

(b) 


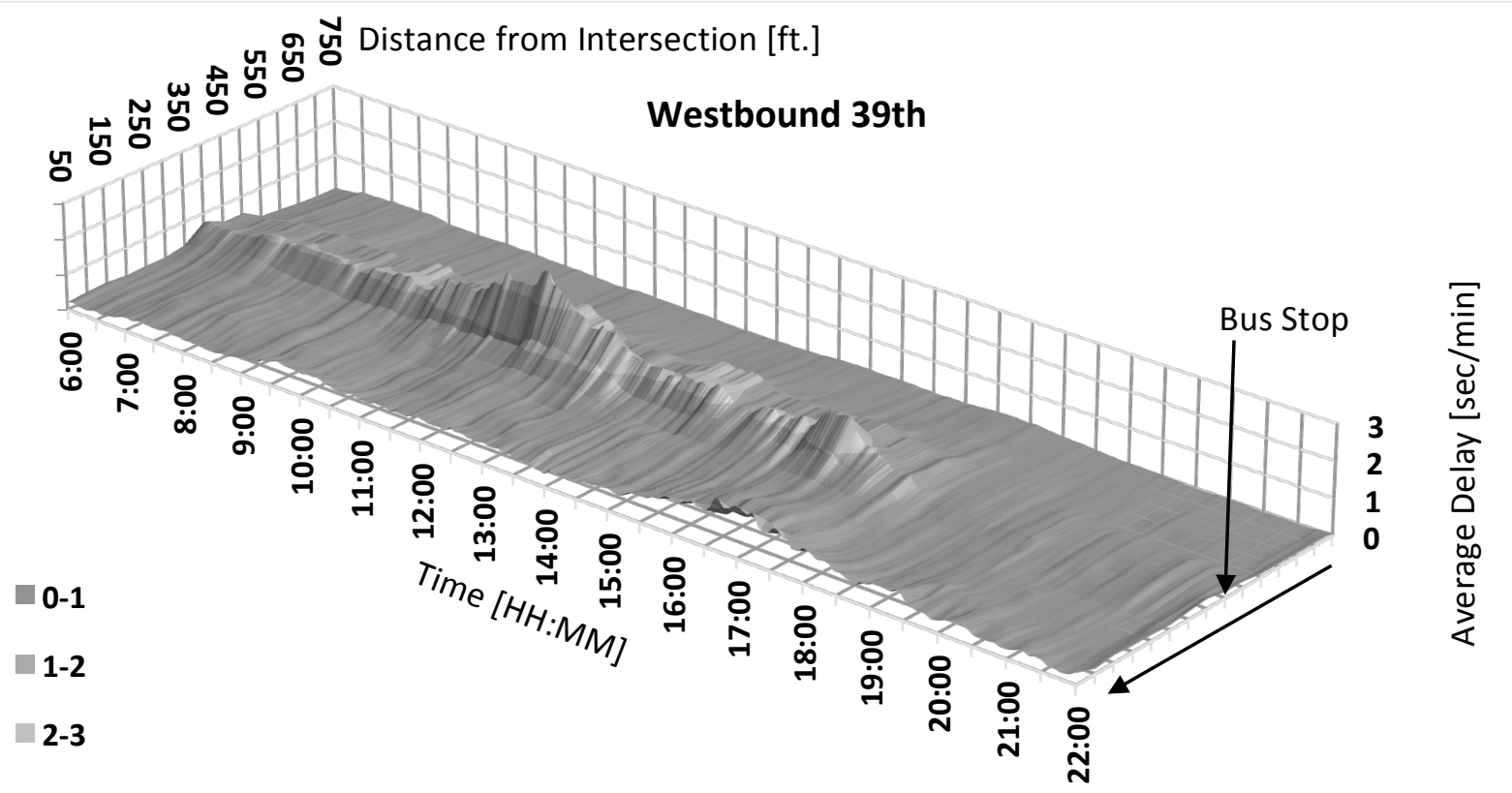

(c)

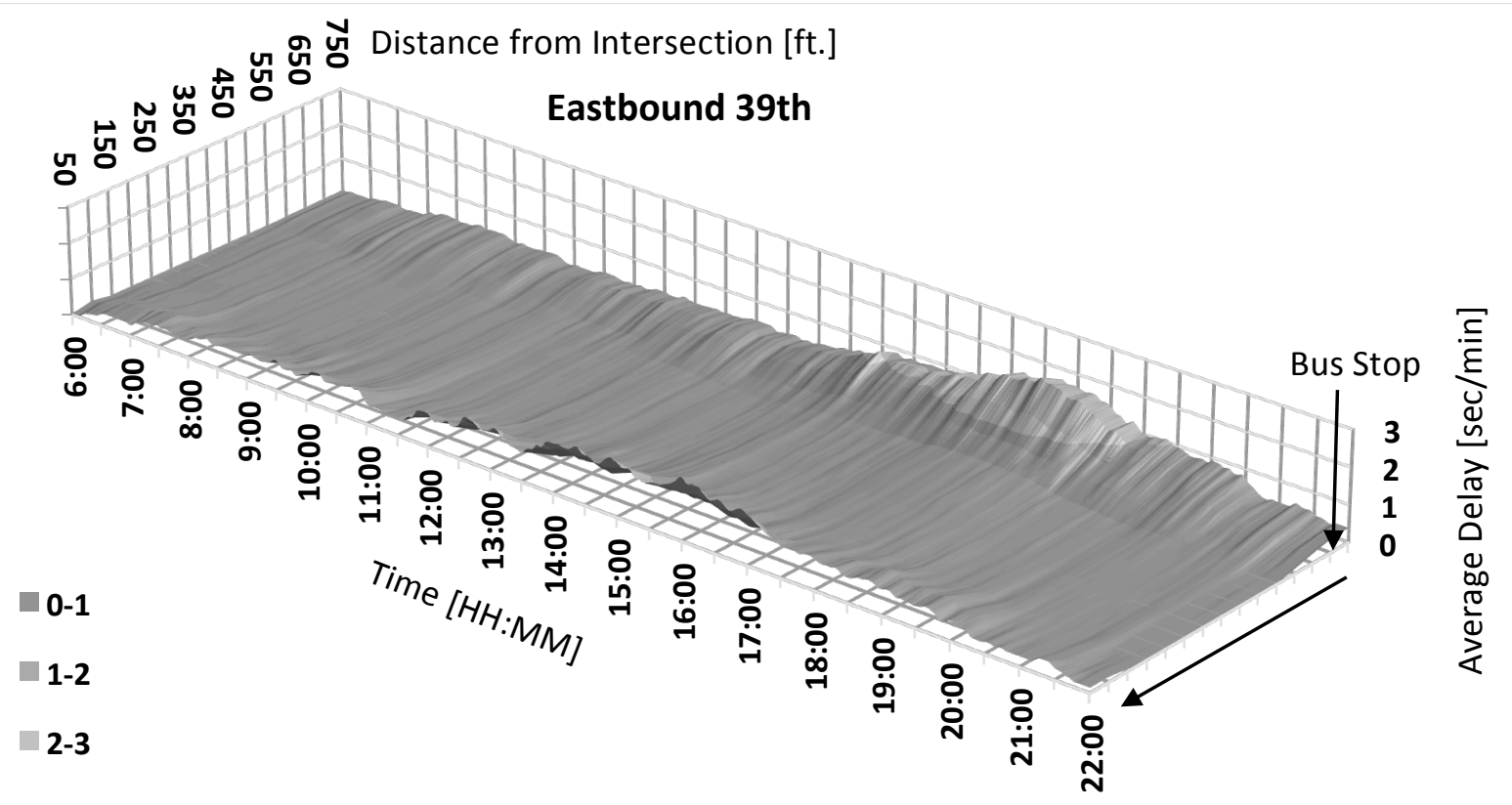

(d)

Figure 11 - Delay in units of seconds per minute per $50 \mathrm{ft}$ interval. (a) westbound approach to $82^{\text {nd }}$ (b) eastbound approach to $82^{\text {nd }}$ (c) westbound approach to $39^{\text {th }}$ and (d) eastbound approach to $39^{\text {th }}$. 
Figure 11 shows how delay changed with both time of day and distance from the intersection.

However, it is difficult to compare the intersections using these graphs. Plots were created for cumulative delay for all times of day plotted against distance from intersection, Figure 12, and for all distances plotted against time of day, Figure 13.

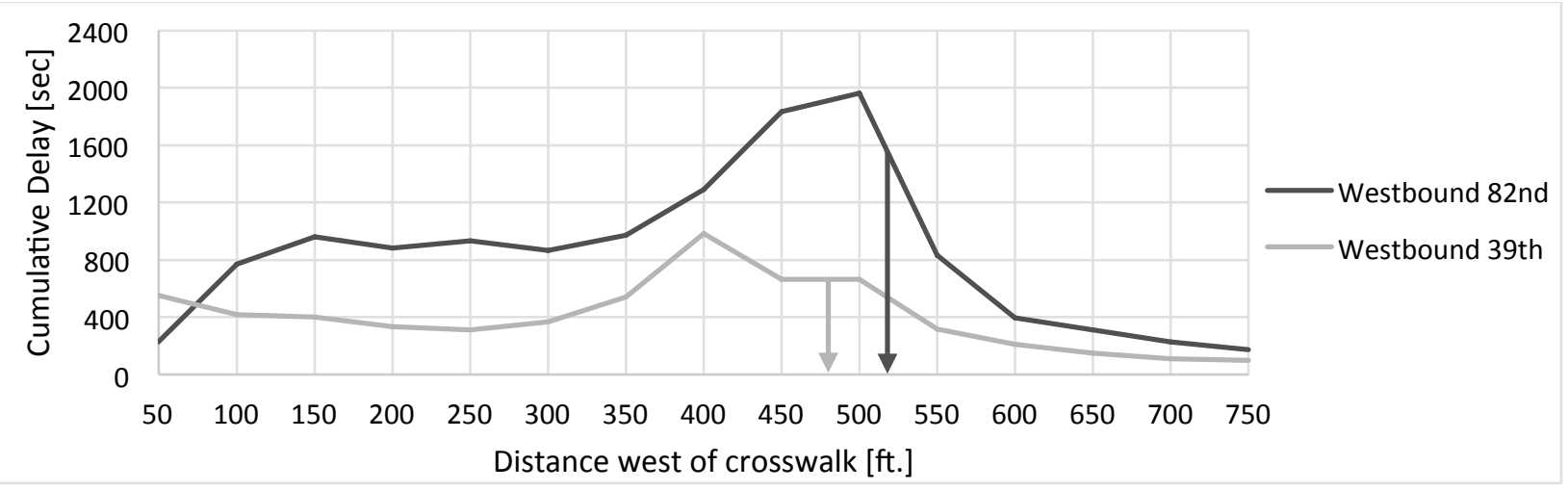

(a)

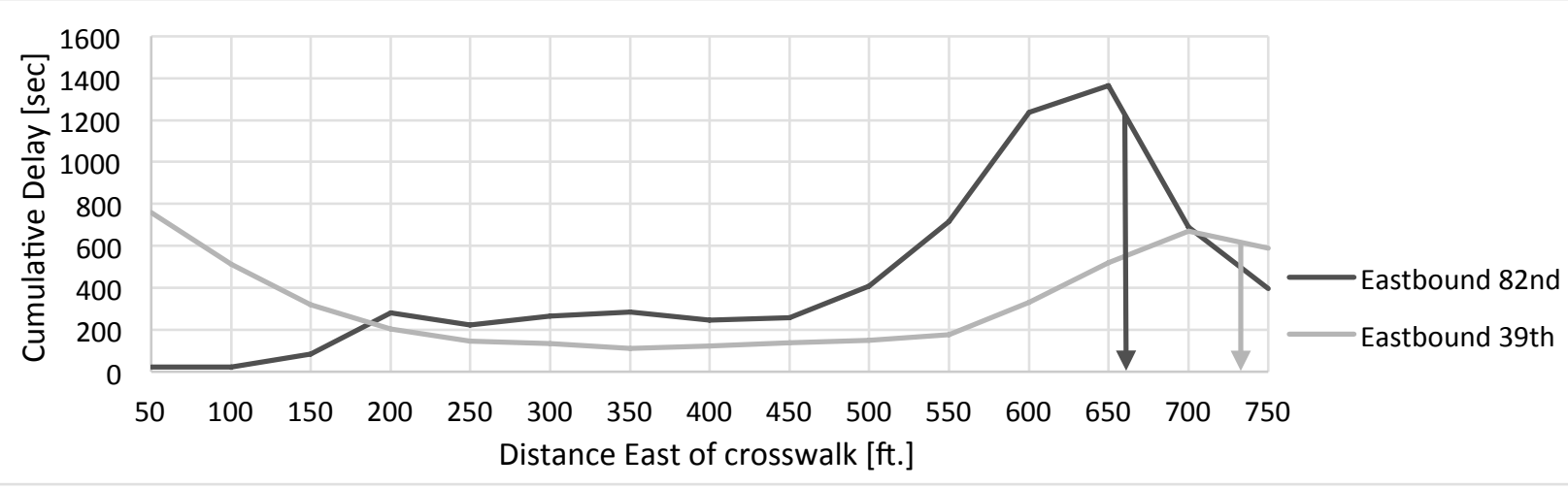

(b)

Figure 12 - Cumulative delay for all times of day plotted against distance upstream of crosswalk. Locations of bus stops upstream of intersection are marked with arrow for (a) westbound travel (b) eastbound travel 


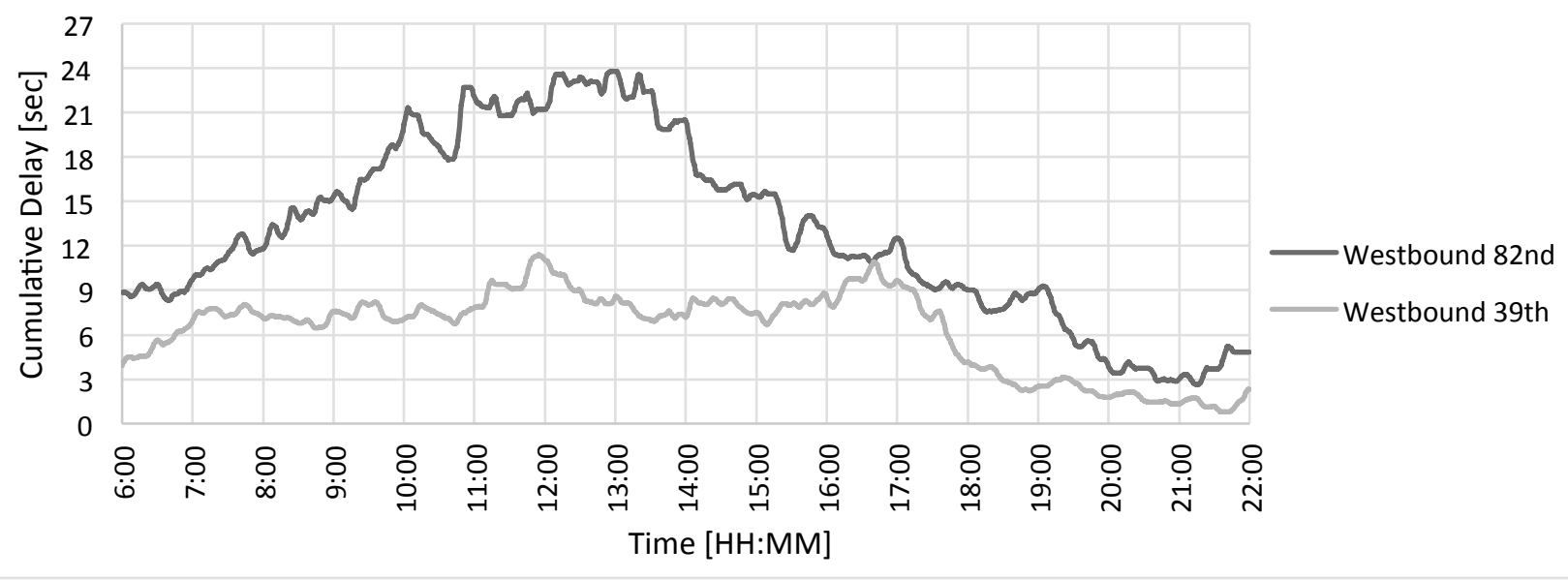

(a)

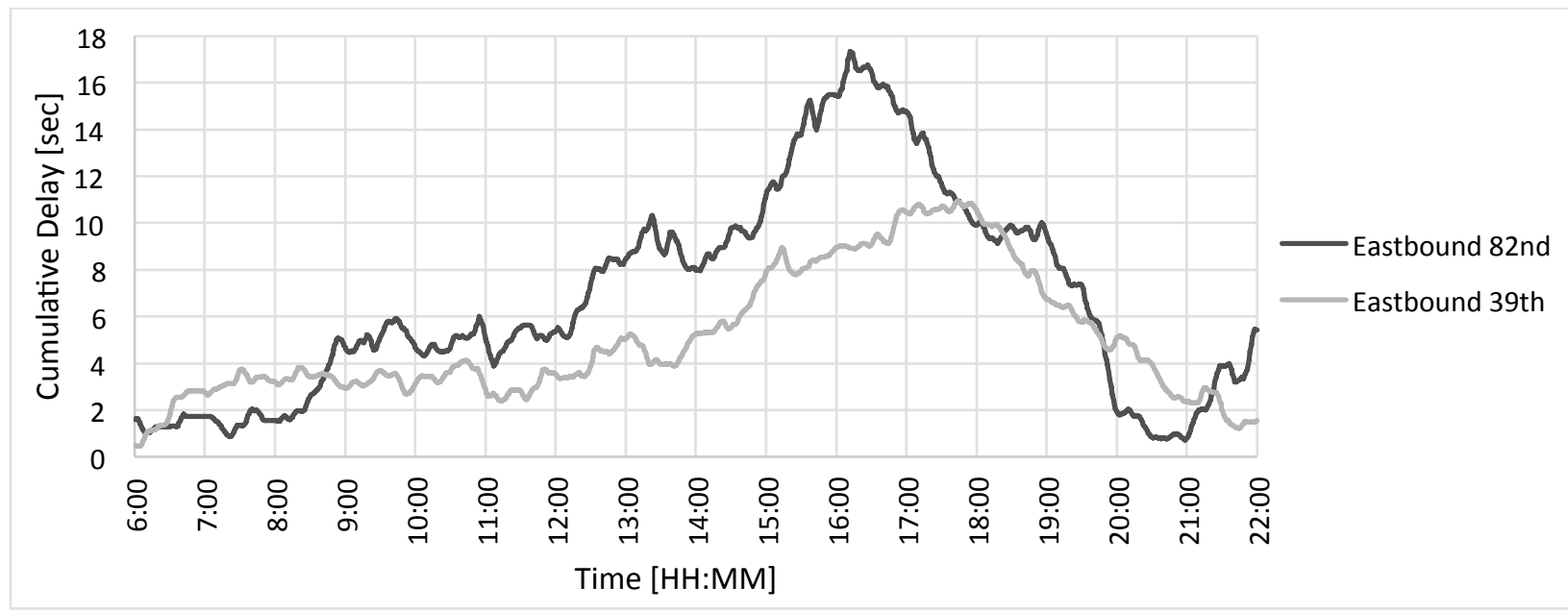

(b)

Figure 13 - Cumulative delay for 50-750 ft. upstream of crosswalk plotted against time of day for (a) westbound travel (b) eastbound travel

Both Figure 12 and Figure 13 show congestion is much greater for the SE $82^{\text {nd }}$ intersection then the SE $339^{\text {th }}$ intersection for both distances and time of day. For a statistical analysis, the delay metric used for comparing intersections was calculated by summing amount of delay between the intersection and the upstream bus stop in $1 \mathrm{hr}$. time intervals then dividing that result by the distance between the bus stop and the intersection. Table 3 will be used to explain this metric. 
Table 3 - Delay in seconds for each $50 \mathrm{ft}$. increment at 6:00 am for westbound approach to SE $82^{\text {nd }}$.

\begin{tabular}{rrrrrrrrrrrrrrrr}
\hline & $\mathbf{5 0}$ & $\mathbf{1 0 0}$ & $\mathbf{1 5 0}$ & $\mathbf{2 0 0}$ & $\mathbf{2 5 0}$ & $\mathbf{3 0 0}$ & $\mathbf{3 5 0}$ & $\mathbf{4 0 0}$ & $\mathbf{4 5 0}$ & $\mathbf{5 0 0}$ & $\mathbf{5 5 0}$ & $\mathbf{6 0 0}$ & $\mathbf{6 5 0}$ & $\mathbf{7 0 0}$ & $\mathbf{7 5 0}$ \\
\hline $\mathbf{6 : 0 0}$ & 0 & 32 & 36 & 31 & 47 & 38 & 42 & 54 & 78 & 77 & 35 & 25 & 19 & 13 & 11 \\
\hline
\end{tabular}

The official location of the upstream bus stop lies $517 \mathrm{ft}$. prior to the intersection; therefore, a sum is taken of delay downstream from that stop to the intersection. Equation 1 and Equation 2 show an example of this calculation for the 6:00 a.m. hour.

Equation 1 - Calculation for seconds of delay for the 6:00 a.m. hour.

Delay $\left[\frac{\mathrm{sec}}{\mathrm{hr} .}\right]=(0+32+36+31+47+38+42+54+78+77)+\frac{17}{50}(35)=446 \frac{\mathrm{sec}}{\mathrm{hr}}$

Equation 2 - Calculation for seconds/foot of delay for the 6:00 a.m. hour.

Delay $\left[\frac{\mathrm{sec}}{h r . * f t}\right]=\frac{446 \mathrm{sec}}{517 \mathrm{ft} .}=0.863 \frac{\mathrm{sec}}{\mathrm{ft}}$

To better understand this metric, the seconds of delay per hour are converted to seconds of delay per minute for the westbound $82^{\text {nd }}$ approach at 6:00 a.m. 446 seconds of delay per hour becomes 7.43 seconds of delay per minute. If it would take a bus an average of 2 minutes to cross $517 \mathrm{ft}$. with free flow travel, it would take the average bus 14.9 seconds longer at 6:00 a.m.

Once this process of calculating delay is applied to each hour and each approach the intersection delay can be compared. The method used to create this metric accounts for one of the most dramatic difference between the four approaches; the distance buses stop prior to the intersection and the intersection itself. Therefore, the delay of the westbound and eastbound approaches can be compared separately to determine whether one intersection geometry has advantages over another and whether that difference is statistically significant. 


\section{Results}

The calculated delay for four intersection approaches is shown in Table 5. The units of delay, seconds per foot per hour, can be interpreted to a total delay time by multiplying the values shown by the distance between the bus stops and intersections. Table 4 shows the distance between the bus stop prior to the intersection and the start of the intersection.

Table 4 - Distance from bus stop to start of intersection

\begin{tabular}{|c|cccc|}
\cline { 2 - 5 } \multicolumn{1}{c|}{} & \multicolumn{2}{c}{ Westbound } & \multicolumn{2}{c|}{ Eastbound } \\
& Powell \& 82nd & Powell \& 39th & Powell \& 82nd & Powell \& 39th \\
\hline Distance [ft.] & 515 & 475 & 665 & 730 \\
\hline
\end{tabular}

Table 5 - Results of Congestion Analysis

\begin{tabular}{|c|cc|cc|}
\cline { 2 - 5 } \multicolumn{1}{c|}{} & \multicolumn{4}{c|}{ Delay [sec/ft./hr.] } \\
\cline { 2 - 5 } \multicolumn{1}{c|}{} & \multicolumn{3}{c|}{ Westbound } & \multicolumn{2}{c|}{ Eastbound } \\
\multicolumn{1}{c|}{} & Powell \& 82nd & Powell \& 39th & Powell \& 82nd & Powell \& 39th \\
\hline $\mathbf{6 : 0 0}$ & 0.863 & 0.492 & 0.101 & 0.146 \\
$\mathbf{7 : 0 0}$ & 1.117 & 0.701 & 0.105 & 0.255 \\
$\mathbf{8 : 0 0}$ & 1.378 & 0.685 & 0.216 & 0.266 \\
$\mathbf{9 : 0 0}$ & 1.704 & 0.751 & 0.386 & 0.254 \\
$\mathbf{1 0 : 0 0}$ & 2.054 & 0.761 & 0.370 & 0.287 \\
$\mathbf{1 1 : 0 0}$ & 2.170 & 0.986 & 0.390 & 0.228 \\
$\mathbf{1 2 : 0 0}$ & 2.318 & 0.976 & 0.554 & 0.319 \\
$\mathbf{1 3 : 0 0}$ & 2.197 & 0.794 & 0.726 & 0.354 \\
$\mathbf{1 4 : 0 0}$ & 1.688 & 0.785 & 0.740 & 0.476 \\
$\mathbf{1 5 : 0 0}$ & 1.397 & 0.780 & 1.092 & 0.657 \\
$\mathbf{1 6 : 0 0}$ & 1.122 & 0.978 & 1.270 & 0.734 \\
$\mathbf{1 7 : 0 0}$ & 0.964 & 0.705 & 0.949 & 0.826 \\
$\mathbf{1 8 : 0 0}$ & 0.831 & 0.303 & 0.761 & 0.684 \\
$\mathbf{1 9 : 0 0}$ & 0.659 & 0.286 & 0.520 & 0.447 \\
$\mathbf{2 0 : 0 0}$ & 0.371 & 0.200 & 0.090 & 0.289 \\
$\mathbf{2 1 : 0 0}$ & 0.406 & 0.149 & 0.226 & 0.153 \\
\hline Average Delay & $\mathbf{1 . 3 2 8}$ & $\mathbf{0 . 6 4 6}$ & $\mathbf{0 . 5 3 1}$ & $\mathbf{0 . 3 9 8}$ \\
[sec/ft./hr.] & & & & \\
\hline
\end{tabular}

Combining the information from Table 4 and Table 5 allows for comment about the length of congestion as compared to free-flow traffic on an approach. For example, on the westbound approach to Powell \& $82^{\text {nd }}$ at $9: 00,1.482 \mathrm{sec} / \mathrm{ft}$./hr. multiplied by $515 \mathrm{ft}$. results in 12 minutes 43 seconds more travel time in the 9:00 hour than is experienced during a time with free-flowing traffic. 
Westbound and eastbound traffic were compared separately due to the differences in flow patterns for each direction. A two-tailed t-test was conducted for dependent (paired) data. For westbound travel, the reduction in delay for the approach to $39^{\text {th }}$ versus the approach to $82^{\text {nd }}$ was statistically significant to $p<0.0001$. Because of this results, we will reject the null hypothesis and accept the alternative hypothesis that an intersection that uses a combination right-through lane for their buses, Figure 2a, may experience more congestion than comparable intersections with a separated right turn lane that buses use, Figure $2 \mathrm{~b}$.

A two-tailed t-test resulted in a statistically significant reduction in delay at SE $39^{\text {th }}$ compared to SE $82^{\text {nd }}(p<0.05)$. Due to this result for eastbound travel, we reject the null hypothesis and accept the alternative hypothesis, which implies that between intersections with a separated right turn lane, buses may experience less delay if they travel in the through lane, Figure $2 b$, rather than the right-turn lane, Figure 2c, before reach a far-side bus stop.

\section{Conclusions \& Recommendation}

Results show that the SE Powell and $82^{\text {nd }}$ intersection experienced higher congestion then the SE Powell and $39^{\text {nd }}$ intersection, and may indicate that the delay experienced by a bus traveling in a separated right turn lane is lower than the delay experienced by buses in a combined right turn/through lane. Additionally, results suggest that the delay may be further reduced by having buses traveling in the through-lane as compared with the turn lane. However, additional research is needed to take into account the impact of passenger movements at bus stops in the study area and to account for characteristics which cannot be controlled. For example, green times differ by intersection, direction of travel, and time of day. While all approaches to both intersections have transit signal priority, SE $82^{\text {nd }}$ Ave. has signal priority over SE Powell in terms of arterial progression while Powell Blvd. has priority over SE $39^{\text {th }}$ Ave. One intersection has SCATS, a program which allows for the potential of remote 
control of an intersection, while the other does not. Finally, while traffic volume is important, the turning movement volumes should be given a higher weight in future analyses. These preliminary results should encourage engineers and planners to examine the options of designing a separated right-turn lane at major intersections and of placing the bus travel lane in the through-lane rather than the rightturn lane of those intersection; these options will likely reduce overall delay experienced by buses at intersections of urban arterials. 


\section{References}

[1] H. S. Levinson, "Analyzing Transit Travel Time Performance," Transportation Research Record no. 915, 1983.

[2] W. Feng, "Analyses of Bus Travel Time Reliability and Transit Signal Priority at the Stop-to-Stop Segment Level.," Dissertation and Thesis, 2014.

[3] O. D. o. Transportation, "Summary of Trends at Automatic Traffic Recorder Stations," Department of Transportation, Portland, 2011.

[4] W. Feng, M. Figliozzi and R. Bertini, "Quantifying the Joint Impacts of Stop Locations, Signalized Intersections, and Traffic Conditions on Bus Travel Time," Transportation Research Record, 2015.

[5] C. o. Portland, "SE Cesar E Chavez Blv @ SE Powell Blv," Office of Transportation, Portland, 2011.

[6] C. o. Portland, "SE 82nd Ave @ SE Powell Blv," Office of Transportation, Portland, 2005.

[7] M. D. Abkowitz and I. Engelstein, "Methods for Maintaining Transit Service Regularity," Transportation Research Record no. 961, pp. 1-8, 1984.

[8] J. G. Strathman, K. J. Dueker, T. Kimpel, R. L. Gerhart, K. Turner, P. Taylor, S. Callas and D. Griffin, "Service Reliability Impacts of Computer-Aided Dispatching and Automatic Vehicle Location Technology: A TriMet Case Study.," Transportation Quarterly, vol. 54, pp. 85-102, 2000.

[9] E. Albright and M. A. Figliozzi, "Factors Influencing Effectiveness of Transit Signal Priority and Late Bus Recovery at Signalized-Intersection Level," 2013.

[10] R. L. Bertini and A. M. El-Geneidy, "Modeling Transit Trip Time Using Archived Bus Dispatch System Data," Journal of Transportation Engineering, vol. 130, pp. 56-67, 2004.

[11] A. M. El-Geneidy, J. Horning and K. J. Krizek, "Analyzing Transit Service Reliability Using Detailed Data from Automatic Vehicular Locator System," Journal of Advanced Transportation, vol. 45, pp. 66-79, 2011.

[12] M. A. Figliozzi and W. Feng, "A Study of headway maintenance for bus routes: causes and effects of "bus bunching" in extensive and congested service areas," Portland State University, Portland, Oregon.

[13] E. I. Diab and A. M. El-Geneidy, "Understanding the impacts of a combination of service improvements strategies on bus running time and passenger"s perception," Transportation Research Part A: Policy and Practice, vol. 46, no. 614-625, 2012.

[14] A. M. El-Geneidy, J. Hourdos and J. Horning, "Bus Transit Service Planning and Operations in a Competitive Environment," Journal of Public Transportation, vol. 12, no. 39-59, 2009.

[15] J. Strathman, K. Dueker, T. Kimpel, R. Gerhart, K. Turner, P. Taylor, S. Callas, D. Griffin and J. Hopper, 
"Automated Bus Dispatching, Operations Control, and Service Reliability: Baseline Analysis," Transportation Research Record, vol. 1666, no. 28-36, 1999.

[16] R. L. Bertini and A. M. El-Geneidy, "Generating Transit Performance Measures with Archived Data," Transportation Research Record, vol. 1841, pp. 109-119, 2003.

[17] R. Hall and N. Vyas, "Buses as a Traffic Probe," Transportation Research Record, vol. 1731, pp. 96$103,2000$.

[18] R. L. Bertini and S. Tantiyanugulchai, "Transit Buses as Traffic Probes: Empirical Evaluation Using Geo-location Data," Transportation Research Record, vol. 1870, pp. 35-45, 2004.

[19] T. B. Glick, W. Feng, R. L. Bertini and M. A. Figliozzi, "Expoloring Applications of Second Generation Archived Transit Data for Estimating Performance Measures and Arterial Travel Speeds," Transportation Research Board, 2014. 